\title{
Human adipocyte differentiation and composition of disease-relevant lipids are regulated by miR-221-3p
}

\section{Ahonen, Maria A.}

2021-01

Ahonen , M A , Asghar , M Y , Parviainen , S J , Liebisch , G , Höring , M , Leidenius , M , Fischer-Posovszky , P, Wabitsch , M , Mikkola , T S , Törnquist , K, Savolainen-Peltonen , H , Haridas , P A N \& Olkkonen , V M 2021 , ' Human adipocyte differentiation and composition of disease-relevant lipids are regulated by miR-221-3p ', Biochimica and Biophysica Acta. Molecular and Cell Biology of Lipids , vol. 1866 , no. 1 , 158841 . https://doi.org/10.1016/j.bbalip.20

http://hdl.handle.net/10138/335659

https://doi.org/10.1016/j.bbalip.2020.158841

cc_by_nc_nd

acceptedVersion

Downloaded from Helda, University of Helsinki institutional repository.

This is an electronic reprint of the original article.

This reprint may differ from the original in pagination and typographic detail.

Please cite the original version. 


\section{Journal Pre-proof}

Human adipocyte differentiation and composition of diseaserelevant lipids are regulated by miR-221-3p

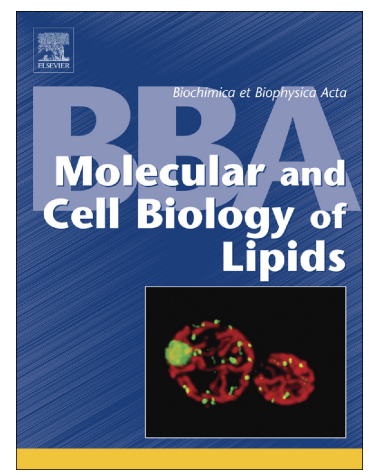

Maria A. Ahonen, Muhammad Yasir Asghar, Suvi J. Parviainen, Gerhard Liebisch, Marcus Höring, Marjut Leidenius, Pamela Fischer-Posovszky, Martin Wabitsch, Tomi S. Mikkola, Kid Törnquist, Hanna Savolainen-Peltonen, P.A. Nidhina Haridas, Vesa M. Olkkonen

PII:

S1388-1981(20)30233-X

DOI: https://doi.org/10.1016/j.bbalip.2020.158841

Reference: BBAMCB 158841

To appear in: BBA - Molecular and Cell Biology of Lipids

Received date: $\quad 5$ August 2020

Revised date: $\quad 7$ October 2020

Accepted date: $\quad 11$ October 2020

Please cite this article as: M.A. Ahonen, M.Y. Asghar, S.J. Parviainen, et al., Human adipocyte differentiation and composition of disease-relevant lipids are regulated by miR-221-3p, BBA - Molecular and Cell Biology of Lipids (2020), https://doi.org/10.1016/ j.bbalip.2020.158841

This is a PDF file of an article that has undergone enhancements after acceptance, such as the addition of a cover page and metadata, and formatting for readability, but it is not yet the definitive version of record. This version will undergo additional copyediting, typesetting and review before it is published in its final form, but we are providing this version to give early visibility of the article. Please note that, during the production process, errors may be discovered which could affect the content, and all legal disclaimers that apply to the journal pertain.

(C) 2020 Published by Elsevier. 
Human adipocyte differentiation and composition of disease-relevant lipids are regulated by miR-221-3p

Maria A. Ahonen ${ }^{1}$, Muhammad Yasir Asghar ${ }^{1}$, Suvi J. Parviainen¹, Gerhard Liebisch², Marcus Höring2 2 Marjut Leidenius ${ }^{3}$, Pamela Fischer-Posovszky4 ${ }^{4}$, Martin Wabitsch ${ }^{4}$, Tomi S. Mikkola ${ }^{5,6}$, Kid Törnquist ${ }^{1,7}$, Hanna Savolainen-Peltonen ${ }^{5,6}$, P.A. Nidhina Haridas ${ }^{1 *}$ and Vesa M.

Olkkonen ${ }^{1,8 *}$

${ }^{1}$ Minerva Foundation Institute for Medical Research, Biomedicum 2U, Helsinki, Finland ${ }^{2}$ Institute of Clinical Chemistry and Laboratory Medicine, Univarsi:y Hospital Regensburg, Germany

${ }^{3}$ Breast Surgery Unit, Comprehensive Cancer Center, Holsinki University Hospital, Helsinki, Finland

${ }^{4}$ Division of Pediatric Endocrinology and Diabє ie., repartment of Pediatrics and Adolescent Medicine, University Medical Center Ulm, ? $\bullet$. many

${ }^{5}$ University of Helsinki and Helsinki Univ rsity Hospital, Obstetrics and Gynecology, Helsinki, Finland

${ }^{6}$ Folkhälsan Research Center, Ric nedicum, Helsinki, Finland

${ }^{7}$ Cell Biology, Faculty of Sci $\sim_{c} c_{t}$ und Engineering, Åbo Akademi University, Turku, Finland

${ }^{8}$ Department of Anatomy, : 7 culty of Medicine, University of Helsinki, Finland

*Authors for correspondence:

Nidhina Haridas PA, Minerva Foundation Institute for Medical Research, Biomedicum 2U, Tukholmankatu 8, FI-00290 Helsinki, Finland

Tel. +358-41-4912214, E-mail: nidhina.haridas@helsinki.fi

Vesa Olkkonen, Minerva Foundation Institute for Medical Research, Biomedicum 2U,

Tukholmankatu 8, FI-00290 Helsinki, Finland

Tel. +358-50-4112297, E-mail: vesa.olkkonen@helsinki.fi 


\section{Abstract}

MicroRNA-221-3p (miR-221-3p) is associated with both metabolic diseases and cancers. However, its role in terminal adipocyte differentiation and lipid metabolism are uncharacterized. miR-221-3p or its inhibitor were transfected into differentiating or mature human adipocytes. Triglyceride (TG) content and adipogenic gene expression were monitored, global lipidome analysis was carried out, and mechanisms underlying the effects of miR-221-3p were investigated. Finally, cross-talk between miR-221-3p expressing adipocytes and MCF-7 breast carcinoma (BC) cells was studiea and miR-221-3p expression in tumor-proximal adipose biopsies from BC patients analyz d. miR-221-3p overexpression inhibited terminal differentiation of adipocytes, as judg d in um reduced TG storage and gene expression of the adipogenic markers SCD1, GLUT4, FA5, DGAT1/2, AP2, ATGL and AdipoQ, whereas the miR-221-3p inhibitor increased $\mathrm{T} i s t$ rage. Knockdown of the predicted miR221-3p target, 14-3-3 $\gamma$, had similar ant ad pogenic effects as miR-221-3p overexpression, indicating it as a potential mediat $r$ of mir-221-3p function. Importantly, miR-221-3p overexpression inhibited de novo lip $\mathrm{o} ; \mathrm{e}$, esis but increased the concentrations of ceramides and sphingomyelins, while $r \in d u_{\imath}$ ing diacylglycerols, concomitant with suppression of sphingomyelin phosphodiesªra,e, ATP citrate lyase, and acid ceramidase. miR-221-3p expression was elevatt. l. $_{\text {. }}+$ amor proximal adipose tissue from patients with invasive BC. Conditioned medium of miR-221-3p overexpressing adipocytes stimulated the invasion and proliferation of BC cells, while medium of the BC cells enhanced miR-221-3p expression in adipocytes. Elevated miR-221-3p impairs adipocyte lipid storage and differentiation, and modifies their ceramide, sphingomyelin, and diacylglycerol content. These alterations are relevant for metabolic diseases but may also affect cancer progression.

Key words: adipose tissue, breast cancer, lipid storage, lipogenesis, microRNA, sphingolipid Funding: This study was supported by the Diabetes Research Foundation (VMO, MAA), Diabetes Wellness Finland (VMO, MAA), the Novo Nordisk Foundation 
(VMO), the Liv och Hälsa Foundation (VMO, KT), Jane and Aatos Erkko Foundation (HS-P), the

State Funding for University Level Research (HS-P), K. Albin Johansson Foundation (MYA), and the German Research Association (FI1700/7-1, Heisenberg program; PF-P.

Disclosure summary: The authors have no conflicts of interest to disclose concerning the work reported in this manuscript.

\section{Introduction}

Adipose tissue (AT) is a bona fide endocrine organ, which regulates energy homeostasis of the body (1). Defects in adipocyte lipid storage and metabolism cu tribute to the pathogenesis of many diseases including insulin resistance, non-alcoholic fa ${ }^{t} v^{l}$,ver disease (NAFLD), type 2 diabetes, and several forms of cancer (2-5). Adipocyt diñentiation is a complex process orchestrated by a series of signaling and transcr ${ }_{r}{ }_{r}$ tir nal events. Adipocytes are initially derived from mesenchymal stem cells, which $\mathrm{c}^{\prime} \mathrm{n}$ mit to form preadipocytes that further differentiate to lipid-laden, mature adipor yte ; $(6,7)$. Mature adipocytes also have the potential to de-differentiate into pluripoten' cells or other cell types $(8,9)$. Dysregulation of adipogenesis or defects in adipocyte li siı storage lead to ectopic lipid accumulation resulting in insulin resistance, fatty live $r$ 'isease, and eventually to type 2 diabetes. In obesity, adipocyte lipid storage caparity s exceeded and abundant lipids are routed to ectopic sites, while in the tumor mic. acids to malignant cells ror cancer progression $(3,4,10)$. Adipocyte lipid composition also plays a role in regulating the function of AT as well as in the progression of disorders such as NAFLD and type 2 diabetes $(11,12)$. Recently a number of studies have shown that microRNAs (miRNAs) plays major roles in maintaining adipocyte physiology and contribute to the development of metabolic diseases (13-16).

MicroRNAs are short 18-25 nucleotide long non-coding RNAs, which alter protein expression via inducing mRNA degradation or inhibiting translation by physically binding to mRNA $(17,18)$. A number of miRNA species are known to regulate adipogenesis, adipocyte lipid 
storage, metabolism, and adipokine secretion by directly targeting protein expression of key genes involved in signaling and transcriptional regulation. MicroRNA-221-3p (miR-221-3p) is one such miRNA shown to affect adipocyte differentiation, metabolism and insulin signaling (19-22). miR-221 expression is elevated in obesity and it is induced upon AT inflammation $(19,21)$. Furthermore, miR-221-3p is considered a cancer-associated miRNA, oncomiR, due to its abundant expression in cancerous tumors as well as in the circulation of patients suffering from several forms of cancer. Consequently, miR-221 and its family member sharing the same seed sequence, miR-222, are emerging as prognostic marker for various cancers (23-25). Although miR-221-3p is known to affect adipocyte metabol $-m$ the mechanisms by which it affects adipocyte differentiation are not known. Mceover, its effect on adipocyte lipid composition has not been investigated. Since miR- $\mathcal{L}_{\llcorner}{ }^{1-2} \rho$ is a potential candidate to identify hitherto unknown mechanisms of adipogen€ sir, adipocyte lipid composition, and their distortions in human diseases, we assess -d I l this study the effects of miR-221-3p on human adipocyte differentiation and lipid corı. nosition, as well as the underlying mechanisms.

\section{Materials and methods}

\subsection{Subjects and study design}

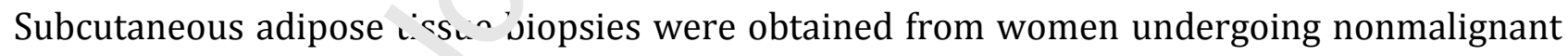
breast surgery (reduction mammoplasty; $n=30$ ). To profile miR-221-3p and adipocyte marker gene expression in breast adipose tissue proximal to tumors (distance to the tumor $<5 \mathrm{~cm}$ ), biopsies were withdrawn from women operated for breast cancer $(n=47)$. The subjects' height, weight, waist and hip circumferences, medical history and use of medications were recorded at the preoperative visit (Table 1). AT biopsies of $1 \mathrm{~g}$ were obtained during the operation from the reduction mammoplasty or mastectomy patients. The biopsies were taken proximally to the breast tumor from the mastectomy patients. The samples were snap frozen in liquid nitrogen and stored at $-80^{\circ} \mathrm{C}$. A written informed consent was acquired from all 
study subjects. The study was approved by the Ethics Committee of Helsinki University Central Hospital.

\subsection{Cell Culture, transfections and collection of conditioned media}

The roles of miR-221-3p and 14-3-3 $\gamma$ (encoded by the gene $Y W H A G$ ) in adipogenesis were studied by transfecting adipocytes with miR-221 mimic or by silencing YWHAG. SimpsonGolabi-Behmel syndrome (SGBS) preadipocytes were cultured and transfected on day 6 of differentiation, followed by differentiation until day 13 or 14 ncce rding to Fischer-Posovszky et al. (26). Transfections were carried out with 100 avi miRNA-221-3p mimic (Qiagen MSY0000278), anti-miR-221-3p (Qiagen MIN0000279) ^r non-targeting siRNA (NT; Qiagen 1027280), or alternatively, with 100 nM YWHAG siki'A (Qiagen SI00100653) or Silencer

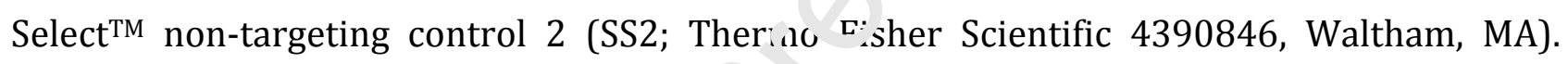
Transfections were performed by using $h$, RNAiMax ${ }^{\mathrm{TM}}$ reagent (Thermo Fisher Scientific). Transfection complexes were incubate. on cells for $48 \mathrm{hrs}$, and the differentiation was continued until mature adipocytes ( $\mathrm{J} 7 y$ 14-16) were lysed or fixed for further experiments.

To study the effect of miP $2 ? \_$sp on metabolism in mature adipocyte, SGBS preadipocytes were differentiated for $1 s$ to 14 days as specified above and transfected with $200 \mathrm{nM}$ miR221-3p mimic or non-targeting control for 72 hrs. Cells were then used for measurement of $\left[{ }^{3} \mathrm{H}\right]$ acetic acid incorporation into lipids or lysed for gene and protein expression or lipidomic analyses. For generating conditioned medium from miR-221-3p transfected mature adipocytes, cells were carefully washed after 48 hrs of transfection, and transfection complexes were replaced with serum free DMEM F-12 (Gibco 31330-038). The freshly added medium was incubated on the cells for 24 hrs. Adipocyte conditioned media (ACM) was collected and centrifuged at $300 \mathrm{xg}$ for $5 \mathrm{~min}$, at $1500 \mathrm{x} \mathrm{g}$ for $10 \mathrm{~min}$ and stored at $-20^{\circ} \mathrm{C}$ until further use for experiments. 
SGBS adipocytes were treated with breast cancer cell conditioned medium (CCM). Michigan Cancer Foundation 7 (MCF-7) cells were cultured with DMEM (Sigma D6429) with 10\% foetal bovine serum (FBS), 2\% L-glutamine, penicillin/streptomycin. Cells were cultured to $>80 \%$ confluency and used for obtaining conditioned medium. For obtaining the CCM, serum free DMEM (SFM; Sigma D5546) was added on MCF-7 cells for 24 hrs, followed by centrifugation as described above for ACM. SGBS cells were differentiated and, once matured, washed carefully. MCF-7 CCM or SFM were added on the adipocytes or 18 hrs and the cells were harvested for following experiments.

\subsection{Invasion assay}

Invasion assays were performed on $6.5 \mathrm{~mm} \mathrm{~d} \mathrm{a}^{r} \iota t$ ter Transwell ${ }^{\mathrm{TM}}$ inserts (Corning Costar, Corning, NY) with pore size of $8 \mu \mathrm{m}$. The neıbranes were coated with $5 \mu \mathrm{g} / \mathrm{cm}^{2}$ human collagen IV and allowed to dry overnight. They were then reconstituted with SFM at $37^{\circ} \mathrm{C}$ for 1 hr prior to the experiment. 50,00C $/ 1\left(r^{-7}\right.$ cells were allowed to migrate/invade in $40 \%$ adipocyte conditioned medium AL:M) in SFM towards $60 \%$ normal medium containing $10 \%$ FBS and 40\% of ACM for 24 h. N iitomycin C, (0.5 mg/ml; Sigma, M4287) was added in both lower and upper chams ${ }^{\text {rs }}$ tn olock proliferation. Next, the cells on top of the membrane were wiped off with a cotton swab. The migrated cells were fixed in $2 \%$ paraformaldehyde for 10 min and stained with $0.1 \%$ crystal violet in $20 \%$ methanol for $5 \mathrm{~min}$. The membranes were rinsed with phosphate-buffered saline (PBS) and water and allowed to dry overnight. The cells were counted at 40x magnification in eight microscopic fields in a straight line bisecting the membrane.

\subsection{Proliferation assay}

Proliferation of MCF-7 cells after ACM incubation (as explained above) was quantified by 
measuring $\left[{ }^{3} \mathrm{H}\right]$ thymidine incorporation. 50,000 cells were seeded on $35-\mathrm{mm}$ plates and allowed to grow for overnight. Next day, the medium was changed to $40 \%$ ACM in culturing medium Four hours prior to the end of each experiment, $0.4 \mu \mathrm{Ci} / \mathrm{ml}\left[{ }^{3} \mathrm{H}\right]$ thymidine was added to each culture plate. The cells were washed three times with PBS, incubated for 10 min with $5 \%$ trichloric acetic acid, and then incubated for 10 min with $0.1 \mathrm{~m} \mathrm{NaOH}$. The samples were transferred into scintillation tubes and high sample load scintillation cocktail Optiphase Hisafe 3 was added. The radioactivity was measured using a Wallac 1414 liquid scintillation counter.

\subsection{Triglyceride measurement and lipid droplet staining}

TG content was measured with an enzymatic GF'-P/P assay kit (Cobas, Roche/Hitachi, Tokyo, Japan) according to the manufacturer's f rr «col. TG levels were normalized to protein content. Transfected and differentiated 'Gb 5 acipocytes were fixed on coverslips with 4\% paraformaldehyde in PBS, followed $\mathrm{K}_{\downarrow}$ ' washıng with cold PBS. The coverslips were stained with Bodipy 493/503 (Molecula P ubes/Thermo Scientific, Eugene, OR) at room temperature for 20 minutes and mu 'inted with Moviol (Calbiochem, La Jolla, CA) containing 5 $\mu \mathrm{g} / \mathrm{ml}$ DAPI (Thermo Scien ific, Molecular Probes) and $50 \mathrm{mg} / \mathrm{ml}$ 1,4-Diazabicyclo-[2.2.2] octane (Sigma-Aldrich, L $\because$ rslips were scanned with 3D Histech Pannoramic scanner (3DHISTECH, Budapest, Hungary) and 20x snapshots taken using CaseViewer (version 2.2;

3DHISTECH). Approximately 500 cells were analyzed by using Fiji software and MRI_Lipid Droplets tool macro (http://dev.mri.cnrs.fr/projects/imagej-macros/wiki/Lipid_Droplets_ Tool).

\subsection{Gene and miRNA expression analyses}

Gene and miR-221-3p expressions were investigated by using quantitative real time PCR (qPCR). Total RNA from SGBS cells or from tissue biopsies was isolated with Qiagen 
(Gaithersburg, MD) kits according to the manufacturer's protocols. SuperScript ${ }^{\circledR}$ VILO ${ }^{\mathrm{T}}{ }^{\mathrm{M}}$ synthesis Kit (Invitrogen, Carlsbad, CA) was used for reverse transcription of cDNA for gene expression analysis. To detect mRNA expression, qPCR was conducted using Roche SYBRGreen ${ }^{\circledR}$ master mix and a LightCycler 480 II Real-Time PCR system (Roche Applied Science, Penzberg, Germany). For analysis, crossing point (Cp) values were calculated from amplification curves and normalized to $\mathrm{Cp}$ values of the housekeeping genes succinate dehydrogenase complex subunit A $(S D H A)$ and actin. Primer sequences are specified in Supplemental Table S1. To measure expression of miR-221-31, RNA was reverse transcribed by using TaqMan ${ }^{\circledR}$ miRNA reverse transcription kit (Appliea Rir systems, Foster City, CA) and qPCR was carried out with TaqMan ${ }^{\circledR}$ microRNA as`ay according to the manufacturer's protocol, using miR-221-3p assay (000524), and RN I44 assay (001094) as a house keeping control.

\subsection{Western blotting}

SGBS protein expression was quanti.î d vy western blotting. Cells were lysed in RIPA buffer (15 mM Tris- $\mathrm{HCl}, \mathrm{pH} 7.4,1 \%$ NI 4 七 1\%, 1.25\% sodium deoxycholate $1.25 \%, 150 \mathrm{mM} \mathrm{NaCl}, 1$ mM EDTA, 1\% SDS). Equal ainou ics of protein were loaded on $10 \%$ or $4-15 \%$ sodium dodecyl sulfate polyacrylamide ${ }_{0}^{-a l s}$ ? $\Gamma$ ast Cast TGX Stain-Free or 4-15\% Mini-Protean TGX Stain-Free gels, BioRad, Hercules, CA). Blotting was done on PVDF membranes using a BioRad Transblot system. Membranes were blocked and probed overnight with anti-SCD1 (Cell Signaling

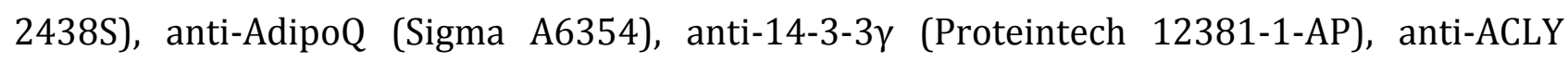
(Santa Cruz Biotechnology SC-517267) or anti-ASAH1 (Santa Cruz Biotechnology SC-136275) in 5\% milk in TBS with $0.5 \%$ Tween-20. Proteins were detected with enhanced chemiluminescence (ECL; Thermo Scientific, Waltham, MA). Image Lab (BioRad) was used to quantify the corresponding protein band intensities normalized to total protein intensity. 


\subsection{Lipidome analysis}

Lipids were extracted using Bligh and Dyer method (27). Internal standards used were PC 28:0, SM 30:1,Cer d18:1/17:0, PE 40:0, DG 28:0, FC7D, CE 17:0, TG 51:0, LPC 13:0, LPE 13:0, Cer 35:1;2, HexCer 35:1;2, PC 0-28:0, PG 28:0, PI 34:0, SM 30:1;2, CE 17:0 and PS 40:0. 10 mM ammonium acetate plus methanol/chloroform (3:1, v/v) (for low mass resolution tandem mass spectrometry), or chloroform/methanol/2-propanol $(1: 2: 4 \mathrm{v} / \mathrm{v} / \mathrm{v})$ with $7.5 \mathrm{mM}$ ammonium formate (for high resolution mass spectrometry) was used for solving the residues. Lipid analysis was conducted by direct flow injectı $~$ analysis (FIA) and a hybrid quadrupole-Orbitrap mass spectrometer (FIA-FTMS; hi h mass resolution) (28) for diglycerides (DG) and TG or a triple quadrupole mass s pecı ometer (FIA-MS/MS; QQQ triple quadrupole) $(29,30)$ for the other classes. Lipid $s_{4}{ }^{3} \mathrm{ci}^{\prime}, \mathrm{s}$ were annotated according to the shorthand notation described previously (31) 'Jita was processed by using macros as previously described (32).

\section{$2.9\left[{ }^{3}\right.$ H]Acetic acid labeling of lipids}

SGBS adipocytes were differenti att. ${ }^{\prime}$ and transfected on 6-well plates as specified above. The cells were then incubated $i$ ith $\left.{ }^{3}{ }^{3} \mathrm{H}\right]$ acetic acid $(1 \mu \mathrm{Ci} /$ well; Amersham, GE Healthcare) in serum free DMEM F-1 $\angle f_{\cap} \wedge$ nrs, after which the cells were washed and harvested into $2 \%$ $\mathrm{NaCl}$. The Bligh and Dyer method was used to extract the lipids (27), followed by thin layer chromatography by using hexane/diethyl ether/acetic acid/ water (70:45:1:0.25) as the running solution. Triolein, diolein and cholesterol were used as standards for TG, DG and cholesterol identification. The corresponding spots were scraped and radioactivity was determined by liquid scintillation counting.

\subsection{Statistical methods}

Shapiro Wilk's test was used to assess normality of the data. Correlations in the patient 
materials were studied by Spearman correlation test. The lipidomics data were studied using multiple t-test and significance determined by Bonferroni-Dunn method. The other in vitro data were analyzed using the Mann-Whitney $U$ or Kruskal Wallis tests for non-normally distributed data and Student's t-test or One-way ANOVA for normally distributed data. Pvalues $\leq 0.05$ were considered significant and standard deviation was reported as standard deviation (SD) from the mean. Statistical analyses were conducted by using GraphPad Prism 8 (GraphPad Software, Inc., La Jolla, CA) or SPSS 25 (IBM SPSS Statistics for Macintosh, Version 25.0. Armonk, NY).

\section{Results}

\section{1 miR-221-3p induces a differentiation defect in humı $n$ r dipocytes}

miR-221-3p is reported to affect adipocyte diff $>r$ tiation when overexpressed at the initial stages of the process (22). However, ne.th $r$ tıe mechanism by which it affects adipocyte differentiation, nor its impact on the ister stages of the differentiation, has been investigated. Hence, we were interested in the ef. 2 .t $f$ miR-221-3p on terminal adipocyte differentiation and the mechanism involved. We $\iota_{\text {. }}$ nsfected miR-221-3p, anti-miR-221-3p or non-targeting (NT) control siRNA to SGBC ad)pocytes on day 6 of the differentiation and continued the differentiation until da, 12 or 14 (Fig. 1A). A drastic, 42\% reduction in the adipocyte TG content was observed upon miR-221-3p overexpression, while anti-miR-221-3p increased the TG content by $44 \%$ in comparison to NT (Fig. 1B), confirming that the endogenous miR-221$3 p$ plays an important role in adipocyte TG storage. Consistently, when compared to the NT controls, the area of imaged lipid droplets per cell was reduced by 64\% upon miR-221-3p transfection, whereas transfection with anti-miR-221-3p induced an increasing trend (+42\%) in the lipid droplet area (Fig. 1C, D). We next wanted to confirm that miR-221-3p causes a differentiation defect, by conducting gene and protein expression analyses. Consistent with the phenotypic change, the mRNA expression of adipocytic differentiation marker genes 
(stearoyl-CoA desaturase-1 - SCD1; glucose transporter 4 - GLUT4; fatty acid synthase - FAS; diacyl glycerol acyl transferase1/2 - DGAT1/2; adipocyte fatty acid binding protein - AP2; adipocyte triglyceride lipase - ATGL; adiponectin - AdipoQ) were significantly decreased in cells transfected with miR-221-3p mimic. Moreover, expression of monoacylglycerol 0acyltransferase (MOGAT) and sterol-regulatory-element-binding protein 1c (SREBF1C) mRNA showed a reducing tendency but did not reach statistical significance (Fig. 2A). To confirm that the impacts of miR-221-3p are present at the level of the corresponding proteins, SCD1 and AdipoQ were analyzed by western blotting; both were sic ificantly downregulated upon miR-221-3p mimic transfection (Fig 2B).

3.2 Adipocyte differentiation defect upon miR-221-3p c 'er' xpression may be mediated by downregulation of $14-3-3 \gamma$

We next wanted to investigate how miR $22:-3 p$ dampens adipocyte differentiation. Several 14-3-3 proteins are connected to diff rentiation of various cell types, and 14-3-3ろ has been

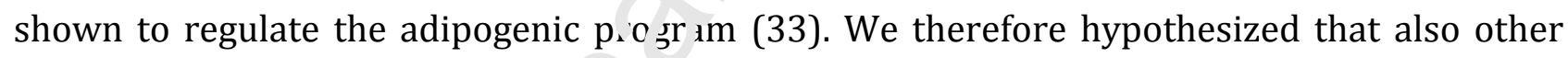
14-3-3 isoforms could play a lolt in adipocyte differentiation. miR-222, which shares an identical seed sequence with mik-221-3p (Fig. 3A), directly targets the YWHAG (encoding 14-

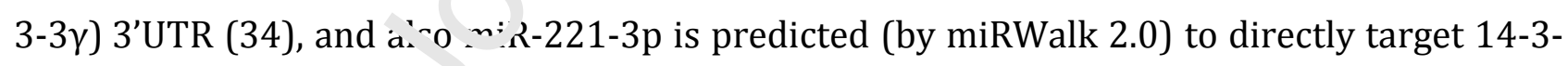
$3 \gamma$ (35). Upon miR-221-3p transfection during SGBS adipocyte differentiation, a significant reduction of 14-3-3 $\gamma$ protein was observed, whereas antimiR-221-3p transfection resulted in

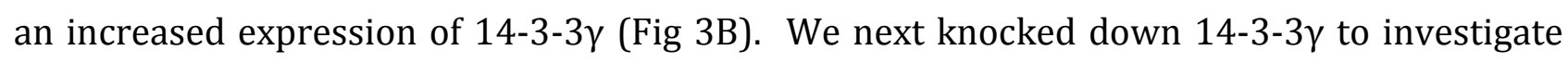
whether this would mediate similar a phenotypic changes as miR-221-3p overexpression does. Indeed, the TG content of SGBS adipocytes was reduced by $25 \%$ and the lipid droplet area per cell by $46 \%$ upon depletion of $14-3-3 \gamma$ (Fig. 3C). Inhibition of the adipogenic differentiation was also reflected in the mRNA markers of adipogenesis, SCD1, GLUT4, FAS and $A H N A K$, which were significantly downregulated upon knockdown of $Y W H A G / 14-3-3 \gamma$ (Fig. 
4A). Since $Y W H A G / 14-3-3 \gamma$ has not been widely studied in human subcutaneous adipose tissue, we wanted to study whether $Y W H A G$ expression correlated with adipogenic markers in human white adipose tissue in vivo. This question was addressed by qPCR analysis of subcutaneous (breast) adipose tissue biopsies from 30 female human subjects. Significant positive correlation of the $Y W H A G$ mRNA with $F A S$, SCD1 and $A H N A K$ was observed (Fig. 4B, C, E).

\section{3 miR-221-3p alters the composition of signaling lipids in humı ? adipocytes}

Since miR-221-3p is connected to adipose tissue dysfuncti $n$. which is characterized by an altered lipid composition and a distortion of th" aumpocytes' differentiation status $(14,22,36,37)$, we wanted to elucidate the effects of miR-221-3p overexpression (72-hr transfection; Fig. 5A) on the lipidome of mature $S_{x}^{\prime} \Gamma S$ adipocytes and on mRNA expression of adipocytic differentiation markers in thrse selıs. The adipogenic mRNAs SCD1, GLUT4, FAS, DGAT1, -2 and ATGL as well as the an i-inflammatory adipokine AdipoQ were all significantly downregulated, whereas the pro-in 1 a matory cytokines (visfatin, interleukin 6 - IL6 and monocyte chemoattractant pro eiı 1 - MCP1) mRNAs were significantly induced (Fig. 5B). Consistent with the mRNA ¿ hse vation, the AdipoQ protein was significantly reduced (Fig.

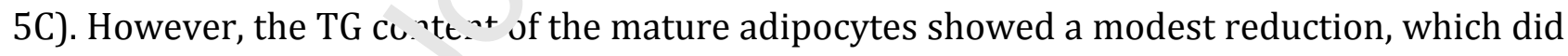
not reach significance (Fig. 5D).

We next carried out a lipidomic analysis of miR-221-3p or NT transfected mature adipocytes. The miR-221-3p overexpressing adipocytes exhibited a significant reduction in the total diacylglycerol (DG) content and an accumulation of ceramides (Cer) and sphingomyelins (SM; Fig. 6A). Significantly affected Cer species were d18:1/22:0, d18:1/24:1, d18:1/20:0, d18:1/24:0, d18:1/18:0, d18:1/26:1; SM species 36:1, 40:1, 40:2, 38:2, 42:2, 42:1, 34:0, 36:2, and DG species 32:2, 34:2, 30:1, 32:1, 32:0, 34:1 (Fig. 6B). Of note, elevation of ceramides in 
white adipose tissue has previously been associated with obesity, insulin resistance and chronic inflammation in metabolic disease (11,37-39), but also in a tumor environment (40). Among the 183 glycerophospholipid species detected, only seven differed significantly between the miR-221-3p transfected and control adipocytes (data not shown), consistent with the view that the functional effect of miR-221-3p is quite specific for the sphingolipids and DG.

\subsection{Ceramide and sphingomyelin accumulation and diacylglycer, defect may be mediated by} downregulation of SMPD1, ASAH1, MOGAT and ACLY

We were interested in the mechanisms that could ha'e ınediated the lipidome alterations observed in miR-221-3p transfected cells. Hence, $v^{\circ}$ = nalyzed by qPCR mRNA levels of a number of enzymes mediating the synthesis of $)$, rer or SM, or the degradation of the latter two (Fig. 7A). The results were consist nt witis the idea that miR-221-3p overexpression dampened the degradation of Cer anc' SM, as suggested by suppression of acid ceramidases 1 and $2(A S A H 1,2)$ and sphingomye.ir. lmosphodiesterase 1 (SMPD1; Fig. 7A). The downregulation of ASAH1 was als, ınnfirmed at the protein level (Fig. 7B). Considering mechanisms underlying the reouction of DG, de novo lipogenesis (DNL) assays (Fig. 7C) suggested that the reas $n: \circ$; most likely in reduced synthesis of DG either through DNL or through a salvage reaction from monoacylglycerol by MOGAT. The MOGAT mRNA was shown to be significantly suppressed (Fig. 7A) in cells overexpressing miR-221-3p. For the de novo pathway we analyzed ATP-citrate lyase (ACLY), an emerging cardiovascular therapy target, which catalyzes a reverse step of the Krebs cycle, converting citrate to acetyl-CoA, the precursor for DNL $(41,42)$. A significant effect on ACLY mRNA was not observed (P=0.06; Fig 7A). However, western blot analysis showed a significant down-regulation of the ACLY protein (Fig. 7B). To conclude, these observations revealed candidate mediators of the impacts of miR-221-3p on adipocyte lipid metabolism, suppression of SMPD1 and ASAH1/2 
providing a plausible explanation for the increase of Cer and SM, and that of MOGAT and ACLY for the reduction of DG. Of note, none of these four enzymes are predicted to be direct targets of miR-221-3p, but are most likely indirectly affected by the miRNA.

\subsection{Mimicking tumor microenvironment enhances miR-221-3p expression}

Elevation of miR-221-3p has been associated with several cancers (43-45) and it is thus considered an oncomiR. Since an altered phenotype characterized by impaired lipid storage is a characteristic of tumor-associated adipocytes $(46,47)$, we axt studied the expression of miR-221-3p in the adipose tissue proximal to breast carcinc na (BC) in a total of 47 subjects undergoing mastectomy. Interestingly, the expression levi of miR-221-3p increased along with the carcinoma grading, grade III displaying the hi ghest expression of the miRNA (Fig. 8A). AdipoQ, which exerts anti-proliferative, an i- 1 r giogenic and pro-apoptoptic effects (48), showed a significant negative correlatio $1 \mathrm{v}$ ith the abundance of miR-221-3p (Fig. 8B). To study whether breast cancer cells couit emit signals controlling the expression of miR-221-3p in adipocytes within the tumor micruf nv rronment, we cultured SGBS adipocytes with MCF-7 BC (adenocarcinoma) cell line con titioned medium (CCM; Fig. 8C). Indeed, the CCM quite significantly enhanced miR-221-jp expression in the adipocytes (Fig. 8E). The increase of

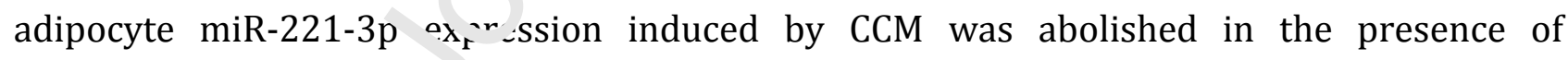
actinomycin D (data not snown), suggesting that the miRNA elevation occurs via endogenous SGBS miRNA synthesis rather than through carry-over from the MCF-7 cells. qPCR analyses revealed that incubation of SGBS adipocytes with CCM significantly induced the mRNAs encoding the pro-inflammatory factors (visfatin; TIMP metallopeptidase inhibitor 1 - Timp1; IL6 and MCP1; Fig. 8F). Furthermore, the adipogenic marker mRNAs SCD1, GLUT4, DGAT1, $A T G L$, and AdipoQ were significantly suppressed by the CCM treatment (Fig. 8G). 
MCF-7 breast cancer cells

Since miR-221-3p expression was increased along with the progression of $\mathrm{BC}$, we tested whether elevated expression of miR-221-3p in adipocytes might affect the phenotype of nearby BC cells. We therefore cultured MCF-7 cells with conditioned medium (ACM) from miR221-3p or NT transfected SGBS adipocytes (Fig. 8D), and measured the migration and proliferation of the MCF-7 cells as endpoints related to cancer progression. Intriguingly, the secretome of miR-221-3p overexpressing adipocytes increased the migration rate of MCF-7 cells by $94 \%$ (Fig. $8 \mathrm{H}$ ) and proliferation by $24 \%$ (Fig. 8I) then compared to ACM from adipocytes transfected with the NT control. This observatic. lf nds support to the idea that elevated expression of miR-221-3p in tumor-proximal, phtıotypically altered adipose tissue may promote cancer progression.

\section{D scussion}

Defects in adipocyte differentiatic: and lipid metabolism are associated with the pathogenesis of a number of comin on diseases (49-57). miRNAs play a crucial role in maintaining adipocyte homeost «Sı, and they can also be used to identify novel molecular mechanisms underlying adi ${ }^{\text {ncy }}$ e function. miR-221 is one such miRNA, the expression of which declines during the -ourse of adipocyte differentiation $(22,58,59)$, which is upregulated in the adipose tissue of obese human subjects (21), but is also associated with a number of cancers (43-45). In this study, the effects of miR-221-3p on terminal adipocyte differentiation and the mechanisms involved were investigated. miR-221-3p or its anti-miR were transfected at an intermediate stage of adipocyte differentiation. The miRNA drastically inhibited the differentiation as evidenced by reduced lipid droplet accumulation and TG content, the anti-miR showing the reverse phenotypic effects (Fig. 1B-D). Genes involved in adipocyte differentiation and lipid synthesis were suppressed by miR-221-3p, which validates the differentiation defect observed (Fig. 2A). Previous studies have indicated that miR-221 
dampens adipocyte differentiation when transfected at the initial stages of the process (22). The impact of miR-221 overexpression on preadipocyte to adipocyte maturation was influenced by whether the cell origin was from lean or obese subjects: miR-221 decreased adipocyte differentiation only in preadipocytes from obese subjects while little effect was seen in preadipocytes of lean origin (60). Importantly, these studies employed miR-221 expression at the initial and pre-initial stages of adipocyte differentiation. In the present study miR-221-3p was overexpressed at the intermediate stage of differentiation, thus targeting the terminal adipocyte differentiation relevant for the obesity-rel. ed dysfunction of adipocytes. Results of this and previous publications indicate that $n^{\prime} \mathrm{R}^{\prime} \cdot 21$ is capable of inhibiting adipocyte differentiation at various stages of the diferutiation cascade and might act through different target genes in a stage-dependt. + tashion. In obese and inflammatory conditions, adipocyte miR-221 expression is ele $r_{\imath} \in \mathbb{I}(19,21)$. This elevation could contribute to an inhibition of healthy adipocyte ex',an ion. Healthy adipocyte expansion and terminal differentiation are crucial to maintá: $n$ AT insulin sensitivity and to limit the pathogenic hypertrophy of insulin resistant adipr,ces (56,61-63). Moreover, elevated adipocyte miR221 expression in tumor microe $1 \mathrm{~V}_{1} \cdot \mathrm{nnm}$ ments, in which adipocytes are altered towards a more immature phenotype with aduced lipid storage capacity $(46,51)$, could promote tumor progression.

The mechanism by which miR-221-3p inhibits adipocyte differentiation and lipid droplet formation was analyzed. One of the predicted targets of miR-221-3p was 14-3-3 $\gamma$, the

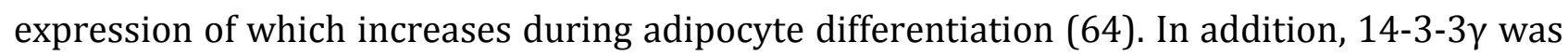
shown to be a direct target of miR-222, the target-selective seed sequence of which is identical to miR-221-3p (34). Indeed, the expression of $14-3-3 \gamma$ was markedly reduced in miR-221-3p overexpressing adipocytes (Fig. 3B), and 14-3-3 $\gamma$ knock-down suppressed the terminal differentiation of human adipocytes, indicating that $14-3-3 \gamma$ may play an important role in the 


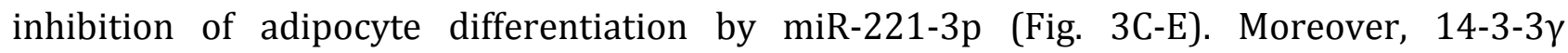
expression correlated positively with adipogenic and lipogenic gene expression in the subcutaneous (breast) adipose tissue of human subjects (Fig. 4B-E), supporting the in vitro findings. 14-3-3 $\gamma$ belongs to a family of related adaptor molecules, which affect the function and localization of a number of signaling components and transcription factors $(65,66)$. 14-33 proteins are involved in a spectrum of cellular processes such as cell survival, motility, insulin signaling, GLUT4 translocation, and DNA damage and repair $(67,68)$. Among the family members 14-3-3ろ was previously shown to accelerate viscer. fat adipogenesis by affecting the key adipogenic transcription factors C/EBP-alpha anc PI AR $\gamma$ in the initial phase of

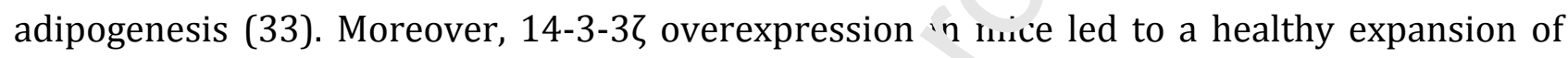
adipocytes, which did not exhibit insulin resistanct $\left(3^{\circ}\right)$ ). However, $14-3-3 \gamma$, in addition to being induced during adipocyte differentiation ( $/ 4)$, is expressed at higher levels in obese adipose tissue compared to lean subject $(67,7 \iota)$. This observation is perplexing since miR221 is also reported to be up-regula 'ad in obesity (21). Elevated expression of $14-3-3 \gamma$ in obese conditions could represent a cur ıp ensatory response to miR-221-3p overexpression, or it could reflect the abundance aid i. igh lipid content of adipocytes under conditions in which the AT is not yet dysfunction ${ }^{\prime}$. m IR-221-3p inhibits adipocyte differentiation as shown during the present study, a. $\mathrm{A}_{\mathrm{f}} \mathrm{R}-221-3 \mathrm{p}$ expression is induced by macrophage-mediated inflammation in adipocytes (19). Altogether, our results may reflect for $14-3-3 \gamma$ a scenario similar to that of 14-3-3ろ: The $\gamma$ isoform could promote healthy AT expansion, and be upregulated as a compensatory response when the AT becomes hypertrophic, inflamed and dysfunctional, a state increasing the abundance of miR-221-3p with an adverse effect on the adipocyte phenotype.

We next progressed to study the effect of miR-221-3p expression in mature adipocytes. Expression of the anti-inflammatory adipokine adiponectin was found to be decreased in the 
miR-221-3p overexpressing adipocytes. Adiponectin levels are reduced in insulin resistance, diabetes, and obesity $(71,72)$. It is further shown to regulate adipogenesis and adipocyte lipid accumulation, thus preventing the accumulation of lipids at ectopic sites (73). Circulating adiponectin is also shown to induce ceramidase activity by binding to adiponectin receptors (AdipoR) 1 and 2, resulting in the reduction of ceramides in cells expressing AdipoR1 and -R2 and improved whole-body insulin sensitivity (74). Suppression of adiponectin expression in miR-221-3p overexpressing cells might thus have an impact on ceramide accumulation in adipocytes. In addition, miR-221 is connected to inflammatio . (75). Similarly, we observed enhanced expression of inflammatory markers upon miR-22:-3r overexpression which could promote sphingolipid accumulation (11). Further st' dies were focused on identifying the lipid composition of miR-221-3p overexpressing ma ur adipocytes. No drastic reduction in TG content was observed in the miR-221-3p tr. $\mathrm{n}$, fı cted cells, however, a reducing tendency was detectable at 72 hrs (Fig. 5D), $\mathrm{c}^{\prime}, \mathrm{nc}$ mitant with a suppression of lipogenic gene expression in these adipocytes (Fig. $5 \mathrm{~B}$ ). These observations indicated that a delipidation process might be underway. Due tc tecunical limitations overexpression of miR-221-3p in mature adipocytes beyond $72 \mathrm{hr}$ i w.s not possible.

Quantitative lipidome ana'ys- was carried out to identify other disease-relevant lipid classes affected by miR-221-3p gc in-of-function. The analysis revealed an increase of Cer and SM, while DG were significantly decreased (Fig. 6A). Gene expression analyses suggested that ceramide synthases were not altered, while the spingomyelin phosphodiesterase SMPD1 and the acid ceramidases $A S A H 1$ and -2 were downregulated. The accumulation of ceramides in miR-221-3p overexpressing mature adipocytes may thus be a result of ASAH1 downregulation, but also suppression of AdipoQ may contribute to this, as adiponectin stimulates ceramidase activity (see above paragraph). Increased ceramides, together with macrophage infiltration, are observed in subcutaneous AT of obese women with increased 
liver fat, suggesting that ceramides may amplify chronic AT inflammation and insulin resistance (38). Moreover, ceramide species including C14:0, C16:0, C16:1 and C18:1 are elevated in the white AT of obese and diabetic patients $(11,39)$. An increase of ceramides was also revealed upon lipidomic profiling of AT from subjects with cancer-related and primary lymphedema, reflecting a pro-inflammatory state of the AT (40). Our observations are consistent with the findings that ASAH1 overexpression in white AT improved whole-body insulin sensitivity and also alleviated hepatic steatosis. C16, C18, C24 and total ceramides were reduced in ASAH1 overexpressing adipose tissue (76). M - reover, ceramides accumulate in pre-eclampsia due to a reduction of ASAH1 protein express:nr (77). Even though ceramides have the capacity to induce apoptosis (78), we obs'rveu no such effect of miR-221-3p overexpression under the present experimental cona. ${ }^{\text {tin }}$ is (data not shown). To conclude, the increase of ceramides in the miR-221-3p or e' $\mathrm{e}$ pressing adipocytes is consistent with suppression of the adipocytes' differenti ter. phenotype and insulin sensitivity, as well as a pro-inflammatory state.

The increase of sphingomyelins ol se 'ed upon miR-221-3p overexpression could in principle be secondary to the increase $\_$f cramides, since a conversion between sphingomyelins and ceramides occurs (79). Hc we er, SM accumulation is often associated with an increase in DG, since the conversion of ceramides to SM by SM synthases occurs via transfer of phosphocholine from phosphatidylcholines (PC) to Cer, thus generating DG (80). On the contrary, DG levels were diminished in miR-221-3p overexpressing adipocytes, and the SM phosphodiesteraae SMPD1 was suppressed. This, together with the observed drop in DNL in these cells, indicates that the observed SM accumulation may not be a result of increased de novo synthesis but rather of a reduced turnover of the lipid. As another mechanism that could potentially reduce the cellular DG, we observed reduced MOGAT expression. This enzyme converts monoacylglycerol back to DG, thus replenishing the cellular DG pool (81). The 
ceramide accumulation in miR-221-3p overexpressing adipocytes was attributed to a reduced expression of acid ceramidase (ASAH1) observed at both mRNA and protein levels. Further analysis also revealed that the miR-221-3p transfected adipocytes expressed reduced levels of ATP citrate lyase (ACLY) (Fig. 7), an enzyme that catalyzes the conversion of citrate to acetyl CoA, the precursor for DNL (82). ACLY deficiency in primary adipocytes was shown to be associated with insulin resistance (83). Moreover, ACLY was shown to activate the carbohydrate response element binding protein (ChREBP) and to regulate both DNL and glucose metabolism in brown adipocytes (84).

Delipidation and reduced adipogenesis of cancer-assoc; iteu adipocytes are observed in many malignancies, including breast cancer $(46,51,85)$. Sir.ce miR-221-3p reduces adipocyte differentiation, the expression of miR-221-3p и as á halyzed in adipose tissue proximal to BC. miR-221-3p expression was elevated in $t^{\prime}{ }^{\prime}$ e 1 reast adipose tissue from patients with grade III invasive BC. AT adiponectin expres ion was reduced in the invasive BC and correlated negatively with miR-221-3p, indicatirg a defect in adipogenesis near the tumor. Plausibly, miR-221-3p could thus play a $r$ sle $n$ reducing adipogenesis in the vicinity of breast tumors and promote a delipidated a'lipc cyte phenotype. Reduced adipogenesis might pave the way for tumor cells to mig: 7 Ł ,oth by partitioning nutrients as well as by reducing spatial constraints $(85,86)$. Moreover, modulation of adipokine expression in the tumor microenvironment could facilitate migration and proliferation of the cancer cells (87-89). Interestingly, conditioned medium (ACM) obtained from miR-221-3p overexpressing adipocytes increased the invasion and proliferation of MCF-7 cells (Fig. 8H, I). Altered adipokine expression or enrichment of nutrients in the ACM might contribute to the enhanced BC cell invasion and proliferation. On the other hand, conditioned medium of MCF-7 cells enhanced the expression of miR-221-3p and pro-inflammatory factors, while reducing adipogenic marker mRNAs, in SGBS adipocytes, suggesting a two-way communication 
between the cancer cells and the near-by adipocytes, which could promote tumor progression.

In conclusion, our results demonstrate a pivotal role of miR-221-3p in the terminal differentiation of human white adipocytes and their lipid composition. Elevated expression of miR-221-3p impairs adipocyte lipid storage and differentiation, as well as modifies their content of key signaling lipids, Cer and DG. These alterations are relevant for metabolic diseases, but may also facilitate cancer progression.

\section{Acknowledgments}

Riikka Kosonen, Anne Ahmanheimo, and Eeva Jääskeläinen re thanked for expert technical assistance.

\section{Reference}

1. Ahima RS, Flier JS. Adipose tissue as an e r'o rine organ. Trends Endocrinol. Metab. 2000;11(8):327-332.

2. Sims EAH, Danforth E, Horton FS. Enaocrine and metabolic effects of experimental obesity in man. Recent Prog. Hır n. Res. 1973;29:457-496.

3. Søvik 0, Vestergaard H, 'ry 'rstad 0, Pedersen 0. Studies of insulin resistance in congenital generalizea' 'ipo iystrophy. Acta Paediatr. Int. J. Paediatr. Suppl. 1996;85(413):2ל 3乙.

4. van der Poorten D, Milner KL, Hui J, Hodge A, Trenell MI, Kench JG, London R, Peduto T, Chisholm DJ, George J. Visceral fat: A key mediator of steatohepatitis in metabolic liver disease. Hepatology 2008;48(2):449-457.

5. Paré M, Darini CY, Yao X, Chignon-Sicard B, Rekima S, Lachambre S, Virolle V, Aguilar-Mahecha A, Basik M, Dani C, Ladoux A. Breast cancer mammospheres secrete Adrenomedullin to induce lipolysis and browning of adjacent adipocytes. $B M C$ Cancer 2020;20(1):784.

6. Min SY, Desai A, Yang Z, Sharma A, DeSouza T, Genga RMJ, Kucukural A, Lifshitz 
LM, Nielsen S, Scheele C, Maehr R, Garber M, Corvera S. Diverse repertoire of human adipocyte subtypes develops from transcriptionally distinct mesenchymal progenitor cells. Proc. Natl. Acad. Sci. U. S. A. 2019;116(36):17970-17979.

7. Rosen ED, MacDougald OA. Adipocyte differentiation from the inside out. Nat. Rev. Mol. Cell Biol. 2006;7(12):885-896.

8. De Matteis R, Zingaretti MC, Murano I, Vitali A, Frontini A, Giannulis I, Barbatelli G, Marcucci F, Bordicchia M, Sarzani R, Raviola E, Cinti S. In vivo physiological transdifferentiation of adult adipose cells. Stem Cells $206^{-} \cdot 27(11): 2761-2768$.

9. Poloni A, Maurizi G, Leoni P, Serrani F, Mancini S, FI 'n+ ini A, Zingaretti MC, Siquini W, Sarzani R, Cinti S. Human dedifferent ateu adipocytes show similar properties to bone marrow-derived mesenchyı' $\rightarrow$, tem cells. Stem Cells 2012;30(5):965-974.

10. Nieman KM, Romero IL, Van Hou' en B, Lengyel E. Adipose tissue and adipocytes support tumorigenesis and met. stasis. Biochim. Biophys. Acta-Mol. Cell Biol. Lipids 2013;1831(10):1533-1541.

11. Chaurasia B, Kaddai VA. Laı- aster GI, Henstridge DC, Sriram S, Galam DLA, Gopalan V, Prakash K VB, Jelan SS, Bulchand S, Tsong TJ, Wang M, Siddique MM, Yuguang G, Sign. 'n.'`r, on K, Mellet NA, Weir JM, Meikle PJ, Bin M. Yassin MS, Shabbir A, Shayman JA, Hirabayashi Y, Shiow SATE, Sugii S, Summers SA. Adipocyte Ceramides Regulate Subcutaneous Adipose Browning, Inflammation, and Metabolism. Cell Metab. 2016;24(6):820-834.

12. Lovric A, Granér M, Bjornson E, Arif M, Benfeitas R, Nyman K, Ståhlman M, Pentikäinen MO, Lundbom J, Hakkarainen A, Sirén R, Nieminen MS, Lundbom N, Lauerma K, Taskinen MR, Mardinoglu A, Boren J. Characterization of different fat depots in NAFLD using inflammation-associated proteome, lipidome and metabolome. Sci. Rep. 2018;8(1):1-14. 
13. Icli B, Feinberg MW. MicroRNAs in dysfunctional adipose tissue: cardiovascular implications. doi:10.1093/cvr/cvx098.

14. Mysore R, Zhou Y, Sädevirta S, Savolainen-Peltonen H, Nidhina Haridas PA, Soronen J, Leivonen M, Sarin A-P, Fischer-Posovszky P, Wabitsch M, Yki-Järvinen H, Olkkonen VM. MicroRNA-192* impairs adipocyte triglyceride storage. Biochim. Biophys. Acta - Mol. Cell Biol. Lipids 2016;1861(4):342-351.

15. Ahonen MA, Haridas PAN, Mysore R, Wabitsch M, Fischer-Posovszky P, Olkkonen VM. miR-107 inhibits CDK6 expression, differentiation, a d lipid storage in human adipocytes. Mol. Cell. Endocrinol. 2019. doi:10.1016/j.m. `e. 018.09.007.

16. Zhao Y, Zhao MF, Jiang S, Wu J, Liu J, Yuan XW, ‘ heı D, Zhang JZ, Zhou N, He J, Fang L, Sun XT, Xue B, Li CJ. Liver governs adipose $\_$गm sdelling via extracellular vesicles in response to lipid overload. Nat. Commun. :02c;11(1):1-17.

17. Zeng Y, Yi R, Cullen BR. MicroRNA, al d sılall interfering RNAs can inhibit mRNA expression by similar mechanis.'`s. Proc. Natl. Acad. Sci. U. S. A. 2003;100(17):97799784.

18. Kim VN. MicroRNA biogel esı - Coordinated cropping and dicing. Nat. Rev. Mol. Cell Biol. $2005 ; 6(5): 376-385$.

19. Mysore R, Orteg. F, I atorre J, Ahonen M, Savolainen-Peltonen H, FischerPosovszky P, Wabitsch M, Olkkonen VM, Fernández-Real JM, Haridas PAN. MicroRNA-221-3p Regulates Angiopoietin-Like 8 (ANGPTL8) Expression in Adipocytes. J. Clin. Endocrinol. Metab. 2017;102(11):4001-4012.

20. Peng J, Zhou Y, Deng Z, Zhang H, Wu Y, Song T, Yang Y, Wei H, Peng J. miR-221 negatively regulates inflammation and insulin sensitivity in white adipose tissue by repression of sirtuin-1 (SIRT1). J. Cell. Biochem. 2017. doi:10.1002/jcb.26589.

21. Meerson A, Traurig M, Ossowski V, Fleming JM, Mullins M, Baier LJ. Human adipose microRNA-221 is upregulated in obesity and affects fat metabolism downstream of 
leptin and TNF- $\alpha$. Diabetologia 2013;56(9):1971-1979.

22. Skårn M, Namløs HM, Noordhuis P, Wang MY, Meza-Zepeda LA, Myklebost 0. Adipocyte differentiation of human bone marrow-derived stromal cells is modulated by MicroRNA-155, MicroRNA-221, and MicroRNA-222. Stem Cells Dev. 2012;21(6):873883.

23. Shah MY, Calin GA. MicroRNAs miR-221 and miR-222: A new level of regulation in aggressive breast cancer. Genome Med. 2011;3(8):56.

24. Visone R, Russo L, Pallante P, De Martino I, Ferraro A teone V, Borbone E, Petrocca F, Alder H, Croce CM, Fusco A. MicroRNAs ( , niP )-221 and miR-222, both overexpressed in human thyroid papillary carcin^ nas, regulate p27Kip1 protein levels and cell cycle. Endocr. Relat. Cancer 2007;14(3, 79; -798.

25. Garofalo M, Quintavalle C, Romano G, N . r,r , ce C, Condorelli G. miR221/222 in Cancer: Their Role in Tumor Progrf ssi n aıd Response to Therapy. Curr. Mol. Med. 2012;12(1):27-33.

26. Fischer-Posovszky P, Newell $F^{\prime}$, , vabitsch M, Tornqvist HE. Human SGBS cells - a unique tool for studies of liun. эn fat cell biology. Obes. Facts 2008;1(4):184-9.

27. Bligh EG, Dyer WJ. A ז 4 PI METHOD OF TOTAL LIPID EXTRACTION AND PURIFICATION. し. $\eta$.' ' $匚$ lochem. Physiol. 1959;37(8):911-917.

28. Höring M, Ejsing (s, Hermansson M, Liebisch G. Quantification of Cholesterol and Cholesteryl Ester by Direct Flow Injection High-Resolution Fourier Transform Mass Spectrometry Utilizing Species-Specific Response Factors. Anal. Chem. 2019;91(5):3459-3466.

29. Liebisch G, Lieser B, Rathenberg J, Drobnik W, Schmitz G. High-throughput quantification of phosphatidylcholine and sphingomyelin by electrospray ionization tandem mass spectrometry coupled with isotope correction algorithm. Biochim. Biophys. Acta - Mol. Cell Biol. Lipids 2004;1686(1-2):108-117. 
30. Liebisch G, Binder M, Schifferer R, Langmann T, Schulz B, Schmitz G. High throughput quantification of cholesterol and cholesteryl ester by electrospray ionization tandem mass spectrometry (ESI-MS/MS). Biochim. Biophys. Acta - Mol. Cell Biol. Lipids 2006;1761(1):121-128.

31. Liebisch G, Vizcaíno JA, Köfeler H, Trötzmüller M, Griffiths WJ, Schmitz G, Spener F, Wakelam MJO. Shorthand notation for lipid structures derived from mass spectrometry. J. Lipid Res. 2013;54(6):1523-1530.

32. Husen P, Tarasov K, Katafiasz M, Sokol E, Vogt J, Baul . oart J, Nitsch R, Ekroos K, Ejsing CS. Analysis of Lipid Experiments (ALEX): A Sof va e Framework for Analysis of High-Resolution Shotgun Lipidomics Data. Martens L, cd. PLoS One 2013;8(11):e79736.

33. Lim GE, Albrecht T, Piske M, Sarai K, Lee JTL, Ra mshaw HS, Sinha S, Guthridge MA, Acker-Palmer A, Lopez AF, Clee SM, Nis o,v „, Johnson JD. 14-3-3ろ coordinates adipogenesis of visceral fat. Nat. Co $n \mathrm{~m}$ in. ¿015;6(1):1-17.

34. Chu YW, Wang CR, Weng FB, Y:n ZJ, Wang C. MicroRNA-222 contributed to cell proliferation, invasion and mig «ti Med. Pharmacol. Sci. 2018.2८( $\left.{ }^{9}\right): 2588-2597$.

35. Dweep H, Sticht C, Pa.'de · P, Gretz N. MiRWalk - Database: Prediction of possible miRNA binding sivs $\because$ walking" the genes of three genomes. J. Biomed. Inform. $2011 ; 44(5): 839-84 /$.

36. Pietiläinen KH, Róg T, Seppänen-Laakso T, Virtue S, Gopalacharyulu P, Tang J, Rodriguez-Cuenca S, Maciejewski A, Naukkarinen J, Ruskeepää AL, Niemelä PS, Yetukuri L, Tan CY, Velagapudi V, Castillo S, Nygren H, Hyötyläinen T, Rissanen A, Kaprio J, Yki-Järvinen H, Vattulainen I, Vidal-Puig A, Orešič M. Association of Lipidome remodeling in the Adipocyte membrane with acquired obesity in humans. PLoS Biol. 2011;9(6). doi:10.1371/journal.pbio.1000623.

37. Chaurasia B, Tippetts TS, Monibas RM, Liu J, Li Y, Wang L, Wilkerson JL, Rufus 
Sweeney C, Pereira RF, Sumida DH, Alan Maschek J, Cox JE, Kaddai V, Lancaster GI,

Siddique MM, Poss A, Pearson M, Satapati S, Zhou H, McLaren DG, Previs SF, Chen

Y, Qian Y, Petrov A, Wu M, Shen X, Yao J, Nunes CN, Howard AD, Wang L, Erion MD,

Rutter J, Holland WL, Kelley DE, Summers SA. Targeting a ceramide double bond improves insulin resistance and hepatic steatosis. Science (80-. ). 2019;365(6451):386392.

38. Kolak M, Westerbacka J, Velagapudi VR, Wågsäter D, Yetukuri L, Makkonen J, Rissanen A, Häkkinen AM, Lindell M, Bergholm R, Ha . sten A, Eriksson P, Fisher RM, Orešič M, Yki-Järvinen H. Adipose tissue inflamn. ^tir $n$ and increased ceramide content characterize subjects with high liver fat $\mathrm{c}^{-}$ntt $\ldots$ it independent of obesity. Diabetes 2007;56(8):1960-1968.

39. Candi E, Tesauro M, Cardillo C, Lena AV , rc cinzari F, Rodia G, Sica G, Gentileschi P, Rovella V, Annicchiarico-Petruzz Alli M, Di Daniele N, Melino G. Metabolic profiling of visceral adipose tissue from chese suojects with or without metabolic syndrome. Biochem. J. 2018;475(5):1019-1'ر3 э.

40. Sedger LM, Tull DL, McConı: 'le MJ, De Souza DP, Rupasinghe TWT, Williams SJ, Dayalan S, Lanzer D, : Tac sie H, Lam TC, Boyages J. Lipidomic Profiling of Adipose

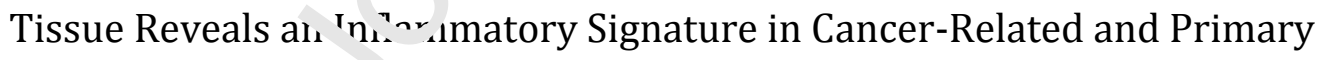
Lymphedema. Maya-Monteiro CM, ed. PLoS One 2016;11(5):e0154650.

41. Ference BA, Ray KK, Catapano AL, Ference TB, Burgess S, Neff DR, Oliver-Williams C, Wood AM, Butterworth AS, Di Angelantonio E, Danesh J, Kastelein JJP, Nicholls SJ. Mendelian Randomization Study of ACLY and Cardiovascular Disease. N. Engl. J. Med. 2019;380(11):1033-1042.

42. Burke AC, Huff MW. ATP-citrate lyase. Curr. Opin. Lipidol. 2017;28(2):193-200.

43. Azar F, Courtet K, Dekky B, Bonnier D, Dameron 0, Colige A, Legagneux V, Théret N. Integration of miRNA-regulatory networks in hepatic stellate cells identifies TIMP3 
as a key factor in chronic liver disease. Liver Int. 2020:liv.14476.

44. Chen Z, Pan T, Jiang D, Jin L, Geng Y, Feng X, Shen A, Zhang L. The lncRNAGAS5/miR-221-3p/DKK2 Axis Modulates ABCB1-Mediated Adriamycin Resistance of Breast Cancer via the Wnt/ $\beta$-Catenin Signaling Pathway. Mol. Ther. - Nucleic Acids 2020;19:1434-1448.

45. Marchionni L, Hayashi M, Guida E, Ooki A, Munari E, Jabboure FJ, Dinalankara W, Raza A, Netto GJ, Hoque MO, Argani P. MicroRNA expression profiling of Xp11 renal cell carcinoma. Hum. Pathol. 2017;67:18-29.

46. Dirat B, Bochet L, Dabek M, Daviaud D, Dauvillier S, Ma, ed B, Wang YY, Meulle A, Salles B, Le Gonidec S, Garrido I, Escourrou G, ' alt i P, Muller C. Cancer-associated adipocytes exhibit an activated phenotype ana nn ribute to breast cancer invasion. Cancer Res. 2011;71(7):2455-2465.

47. Lee J, Hong BS, Ryu HS, Lee H-B, J ¿e I, F ark IA, Kim J, Han W, Noh D-Y, Moon H-G. Transition into inflammatory cá.`cer-associated adipocytes in breast cancer microenvironment requires mi $\approx$ ol iNA regulatory mechanism. Ahmad A, ed. PLoS One 2017;12(3):e0174126.

48. Dalamaga M, Diakop ' 'lo, KN, Mantzoros CS. The role of adiponectin in cancer: A

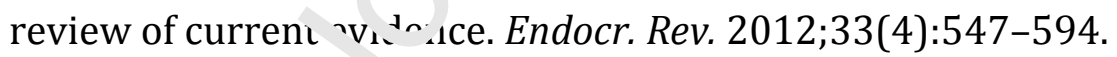

49. Lotta LA, Gulati P, Day FR, Payne F, Ongen H, Van De Bunt M, Gaulton KJ, Eicher JD, Sharp SJ, Luan J, De Lucia Rolfe E, Stewart ID, Wheeler E, Willems SM, Adams C, Yaghootkar H, Sharp SJ, Forouhi NG, Kerrison ND, Sims M, Lucarelli DME, Deloukas P, McCarthy MI, Arriola L, Balkau B, Barricarte A, Boeing H, Franks PW, Gonzalez C, Grioni S, Kaaks R, Key TJ, Navarro C, Nilsson PM, Overvad K, Palli D, Panico S, Quirós JR, Rolandsson 0, Sacerdote C, Salamanca-Fernández E, Slimani N, Tjonneland A, Tumino R, Spijkerman AMW, Van Der A DL, Van Der Schouw YT, Riboli E, Semple RK, Stears A, George S, Walker M, Gurnell E, Maguire D, Mukhtar 
R, Nag S, Adler A, Soeters MR, Laji K, Watt A, Aylwin S, Johnson A, Rayman G, Hanna F, Ellard S, Ross R, Blaslov K, Duvnjak LS, Khaw KT, Johnson AD, Frayling T, Perry JRB, Dermitzakis E, Barroso I, Wareham NJ, Savage DB, Langenberg C, O’Rahilly S, Scott RA. Integrative genomic analysis implicates limited peripheral adipose storage capacity in the pathogenesis of human insulin resistance. Nat. Genet. 2017;49(1):17-26.

50. Chu AY, Deng X, Fisher VA, Drong A, Zhang Y, Feitosa MF, Liu CT, Weeks O, Choh AC, Duan Q, Dyer TD, Eicher JD, Guo X, Heard-Costa N Kacprowski T, Kent JW, Lange LA, Liu X, Lohman K, Lu L, Mahajan A, O’Conn 'll ' R, Parihar A, Peralta JM, Smith A V., Zhang Y, Homuth G, Kissebah AH, F lllucrg J, Laqua R, Launer LJ, Nauck M, Olivier M, Peyser PA, Terry JG, Wojczynsı : M X, Yao J, Bielak LF, Blangero J, Borecki IB, Bowden DW, Carr JJ, Czerwi nsk SA, Ding J, Friedrich N, Gudnason V, Harris TB, Ingelsson E, Johnson $\boldsymbol{A}$ D, Laruia SLR, Langefeld CD, Lind L, Liu Y, Mitchell BD, Morris AP, Mosl€ `TH, Rotter JI, Shuldiner AR, Towne B, Völzke H, Wallaschofski H, Wilson JG, t.l''s ,n M, Lindgren CM, Goessling W, Cupples LA, Steinhauser ML, Fox CS. Mui 'iethnic genome-wide meta-analysis of ectopic fat depots identifies loci associat $\mathrm{t} \mathrm{w}$ ch adipocyte development and differentiation. Nat. Genet. 2017;49(1):125-:3し.

51. Tan J, Buache E, Cnenard MP, Dali-Youcef N, Rio MC. Adipocyte is a non-trivial, dynamic partner of breast cancer cells. Int. J. Dev. Biol. 2011;55(7-9):851-859.

52. Barroso I, Gurnell M, Crowley VEF, Agostini M, Schwabe JW, Soos MA, Maslen GL, Williams TDM, Lewis H, Schafer AJ, Chatterjee VKK, O’Rahilly S. Dominant negative mutations in human PPAR $\gamma$ associated with severe insulin resistance, diabetes mellitus and hypertension. Nature 1999;402(6764):880-883.

53. Majithia AR, Flannick J, Shahinian P, Guo M, Bray MA, Fontanillas P, Gabriel SB, Manning AK, Hartl C, Agarwala V, Green T, Banks E, DePristo M, Poplin R, Shakir 
K, Fennell T, Njølstad PR, Altshuler D, Burtt NP, Fuchsberger C, Kang HM, Sim X,

Ma C, Locke AE, Blackwell T, Jackson A, Teslovich TM, Stringham H, Chines PS, Kwan P, Huyghe JR, Tan A, Jun G, Stitzel M, Bergman RN, Bonnycastle L,

Tuomilehto J, Collins FS, Scott LJ, Mohlke KL, Abecasis G, Boehnke M, Strom T, Gieger C, Müller-Nurasyid M, Grallert H, Kriebel J, Ried J, De Angelis MH, Huth C, Meisinger C, Peters A, Rathmann W, Strauch K, Meitinger T, Kravic J, Algren P, Ladenvall C, Toumi T, Isomaa B, Groop L, Gaulton K, Moutsianas L, Rivas M, Pearson R, Mahajan A, Prokopenko I, Kumar A, Perry , Howie B, Van De Bunt M, Small K, Lindgren CM, Lunter G, Robertson N, Raync - V , Morris A, Buck D, Hattersley A, Spector T, McVean G, Frayling T, ' lol..elly P, McCarthy M, Gupta N, Taylor H, Fox E, Newton-Cheh C, Wilson JG, L'Dr nnell CJ, Kathiresan S, Hirschhorn J, Seidman JG, Seidman C, Williams AL, Jar,o’s SBR, Moreno-Macías H, HuertaChagoya A, Churchhouse C, Luna _M Gaı cía-Ortíz H, Gómez-Vázquez MJ, Estrada K, Mercader JM, Ripke S, Neal، B, Stram DO, Fernández-López JC, Romero-Hidalgo S, Aguilar-Delfín I, Martínez-_I _r rández A, Centeno-Cruz F, Mendoza-Caamal E, Monsalve CR, Islas-Andr ıdc S, Córdova E, Rodríguez-Arellano E, Soberón X, González-Villalpandc ME Monroe K, Wilkens L, Kolonel LN, Le Marchand L, Riba L, Ordóñez-Sánc: $e_{\llcorner} M_{2}$, Guillén RR, Cruz-Bautista I, Rodríguez-Torres M, MuñozHernández LL, Sáenz T, Gómez D, Alvirde U, Onofrio RC, Brodeur WM, Gage D, Murphy J, Franklin J, Mahan S, Ardlie K, Crenshaw AT, Winckler W, MacArthur DG, Florez JC, Haiman CA, Henderson BE, Aguilar-Salinas CA, González-Villalpando C, Orozco L, Tusié-Luna T, Almeida M, Asimit JL, Atzmon G, Barber M, Beer NL, Bell GI, Below J, Blackwell T, Blangero J, Bowden DW, Chambers J, Chen H, Chen P, Choi S, Cingolani P, Cornes BK, Cox N, Day-Williams AG, Duggirala R, Dupuis J, Dyer T, Feng S, Fernandez-Tajes J, Ferreira T, Fingerlin TE, Frayling TM, Gamazon ER, Ghosh S, Gloyn A, Grossman RL, Grundstad J, Hanis C, Heath A, Highland H, 
Hirokoshi M, Huh IS, Ikram K, Jablonski KA, Kim YJ, Kato N, Kim J, King CR, Kooner J, Kwon MS, Im HK, Laakso M, Lam KKY, Lee J, Lee S, Lee S, Lehman DM, Li H, Liu X, Livne OE, Maller JB, Maxwell TJ, Mazoure A, McCarthy MI, Meigs JB, Min B, Musani S, Nagai Y, Ng MCY, Nicolae D, Oh S, Palmer N, Park T, Pollin TI, Reich D, Rivas MA, Seielstad M, Cho YS, Tai ES, Sladek R, Smith P, Tachmazidou I, Torres J, Trubetskoy V, Willems SM, Wiltshire S, Won S, Wood AR, Xu W, Teo YY, Yoon J, Lee JY, Zawistowski M, Zeggini E, Zhang W, Zöllner S, Rosen ED, Scolnick E. Rare variants in PPARG with decreased activity in adipocyte $a$ ' ferentiation are associated with increased risk of type 2 diabetes. Proc. Natl. Acad. S ci. J. S. A.

2014;111(36):13127-13132.

54. Neeland IJ, Turer AT, Ayers CR, Powell-Wile, Tr I, Vega GL, Farzaneh-Far R, Grundy SM, Khera A, McGuire DK, De Lc m. : JA. Dysfunctional adiposity and the risk of prediabetes and type 2 diabetes; 10 sest adults. JAMA - J. Am. Med. Assoc. 2012;308(11):1150-1159.

55. Isakson $\mathbf{P}$, Hammarstedt A, G a it; ison B, Smith U. Impaired preadipocyte differentiation in human a oa minal obesity: Role of Wnt, tumor necrosis factor- $\alpha$, and inflammation. Diabetes $2.0(7 ; 58(7): 1550-1557$.

56. Morley TS, Xia Ji: Schr, rer PE. Selective enhancement of insulin sensitivity in the mature adipocyte is sufficient for systemic metabolic improvements. Nat. Commun. 2015;6. doi:10.1038/ncomms8906.

57. Agarwal AK, Arioglu E, de Almeida S, Akkoc N, Taylor SI, Bowcock AM, Barnes RI, Garg A. AGPAT2 is mutated in congenital generalized lipodystrophy linked to chromosome 9q34. Nat. Genet. 2002;31(1):21-23.

58. Xie H, Lim B, Lodish HF. MicroRNAs induced during adipogenesis that accelerate fat cell development are downregulated in obesity. Diabetes 2009;58(5):1050-7.

59. Ortega FJ, Moreno-Navarrete JM, Pardo G, Sabater M, Hummel M, Ferrer A, 
Rodriguez-Hermosa JI, Ruiz B, Ricart W, Peral B, Fernández-Real JM. MiRNA

expression profile of human subcutaneous adipose and during adipocyte differentiation. PLoS One 2010;5(2). doi:10.1371/journal.pone.0009022.

60. Chou W-W, Wang Y-T, Liao Y-C, Chuang S-C, Wang S-N, Juo S-HH. Decreased microRNA-221 is associated with high levels of TNF- $\alpha$ in human adipose tissue-derived mesenchymal stem cells from obese woman. Cell. Physiol. Biochem. 2013;32(1):127-37.

61. Senol-Cosar O, Flach RJR, Distefano M, Chawla A, Nicoloro S, Straubhaar J, Hardy OT, Noh HL, Kim JK, Wabitsch M, Scherer PE, Czech $\mathbf{M}_{\mathbf{1}}$ Tenomodulin promotes human adipocyte differentiation and beneficial viscera. эd' pose tissue expansion. Nat. Commun. 2016;7(1):1-13.

62. Kusminski CM, Holland WL, Sun K, Park J, S, Irs, in SB, Lin Y, Askew GR, Simcox JA, McClain DA, Li C, Scherer PE. MitoNEET $d r_{\imath} v$ ən alterations in adipocyte mitochondrial activity reveal a crucial adaptive pr, ce $s$ that preserves insulin sensitivity in obesity. Nat. Med. 2012;18(10):1539-1551.

63. Sun K, Kusminski CM, Scherє $r$ ?l . Adipose tissue remodeling and obesity. J. Clin. Invest. 2011;121(6):2094-161

64. Gojanovich AD, Bustc - D I i, Uhart M. Differential expression and accumulation of 143-3 paralogs in 3 `2- $^{1}$ preadipocytes and differentiated cells. Biochem. Biophys. Reports 2016;7:106-112.

65. Morrison DK. The 14-3-3 proteins: integrators of diverse signaling cues that impact cell fate and cancer development. Trends Cell Biol. 2009;19(1):16-23.

66. Brunet A, Kanai F, Stehn J, Xu J, Sarbassova D, Frangioni J V., Dalal SN, Decaprio JA, Greenberg ME, Yaffe MB. 14-3-3 transits to the nucleus and participates in dynamic nucleocytoplasmic transport. J. Cell Biol. 2002;156(5):817-828.

67. Ramm G, Larance M, Guilhaus M, James DE. A role for 14-3-3 in insulin-stimulated GLUT4 translocation through its interaction with the RabGAP AS160. J. Biol. Chem. 
2006;281(39):29174-29180.

68. Pennington K, Chan T, Torres M, Andersen J. The dynamic and stress-adaptive signaling hub of 14-3-3: emerging mechanisms of regulation and context-dependent protein-protein interactions. Oncogene 2018;37(42):5587-5604.

69. Boden G, Duan X, Homko C, Molina EJ, Song W, Perez O, Cheung P, Merali S. Increase in endoplasmic reticulum stress-related proteins and genes in adipose tissue of obese, insulin-resistant individuals. Diabetes 2008;57(9):2438-2444.

70. Insenser M, Montes-Nieto R, Vilarrasa N, Lecube A, SI ‘ó R, Vendrell J, EscobarMorreale HF. A nontargeted proteomic approach to th st 1 dy of visceral and subcutaneous adipose tissue in human obesity. M. l. cuil. Endocrinol. 2012;363(12):10-19.

71. Kern PA, Di Gregorio GB, Lu T, Rassouli N, F anganathan G. Adiponectin expression from human adipose tissue: Relatic . itc obısity, insulin resistance, and tumor necrosis factor- $\alpha$ expression. Diabetes 2C ?3;52(`):1779-1785.

72. Ohashi K, Ouchi N, Matsuzau a Y. Anti-inflammatory and anti-atherogenic properties of adiponectin. Biochimie :.0 $\perp^{2}: 94(10): 2137-2142$.

73. Fu Y, Luo N, Klein RL, Far vey WT. Adiponectin promotes adipocyte differentiation, insulin sensitivity, 71. ${ }^{1}$.pid accumulation. J. Lipid Res. 2005;46(7):1369-79.

74. Holland WL, Xia JY, Johnson JA, Sun K, Pearson MJ, Sharma AX, Quittner-Strom E, Tippetts TS, Gordillo R, Scherer PE. Inducible overexpression of adiponectin receptors highlight the roles of adiponectin-induced ceramidase signaling in lipid and glucose homeostasis. Mol. Metab. 2017;6(3):267-275.

75. Zhao D, Zhuang N, Ding Y, Kang Y, Shi L. MiR-221 activates the NF- $\kappa B$ pathway by targeting A20. Biochem. Biophys. Res. Commun. 2016;472(1):11-8.

76. Xia JY, Holland WL, Kusminski CM, Sun K, Sharma AX, Pearson MJ, Sifuentes AJ, McDonald JG, Gordillo R, Scherer PE. Targeted Induction of Ceramide Degradation 
Leads to Improved Systemic Metabolism and Reduced Hepatic Steatosis. Cell Metab. 2015;22(2):266-278.

77. Melland-Smith M, Ermini L, Chauvin S, Craig-Barnes H, Tagliaferro A, Todros T, Post M, Caniggia I. Disruption of sphingolipid metabolism augments ceramide-induced autophagy in preeclampsia. Autophagy 2015;11(4):653-669.

78. Yabu T, Shiba H, Shibasaki Y, Nakanishi T, Imamura S, Touhata K, Yamashita M. Stress-induced ceramide generation and apoptosis via the phosphorylation and activation of nSMase1 by JNK signaling. Cell Death Differ. : 015;22(2):258-273.

79. Huitema K, Van Den Dikkenberg J, Brouwers JFHM, Yo' chuis JCM. Identification of a family of animal sphingomyelin synthases. EMBO: 2vư 4;23(1):33-44.

80. Cerbón J, López-Sánchez R del C. Diacylglyceı ㄱ 로nerated during sphingomyelin synthesis is involved in protein kinase $\mathrm{C}$ a : t' $v{ }^{\prime}$ tion and cell proliferation in MadinDarby canine kidney cells. Biochem J; ¿ 00 s.

81. Yen CLE, Stone SJ, Cases S, ZhG $、$ P, Farese R V. Identification of a gene encoding MGAT1, a monoacylglycerol ac Jl rŕ nsferase. Proc. Natl. Acad. Sci. U. S. A. 2002;99(13):8512-8517.

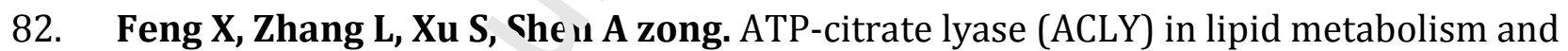
atherosclerosis: $\mathrm{s}^{\urcorner} \mathrm{u}_{\mathbf{1}}^{\mathrm{N}} \mathrm{d}$ ated review. Prog. Lipid Res. 2020;77. doi:10.1016/j.plipres.2019.101006.

83. Fernandez S, Viola JM, Torres AM, Wallace M, Trefely S, Zhao S, Affronti HC, Gengatharan JM, Guertin DA, Snyder NW, Metallo CM, Wellen KE. Adipocyte ACLY Facilitates Dietary Carbohydrate Handling to Maintain Metabolic Homeostasis in Females. Cell Rep. 2019;27(9):2772-2784.e6.

84. Martinez Calejman C, Trefely S, Entwisle SW, Luciano A, Jung SM, Hsiao W, Torres A, Hung CM, Li H, Snyder NW, Villén J, Wellen KE, Guertin DA. mTORC2-AKT signaling to ATP-citrate lyase drives brown adipogenesis and de novo lipogenesis. Nat. 
Commun. 2020;11(1):1-16.

85. Andarawewa KL, Motrescu ER, Chenard MP, Gansmuller A, Stoll I, Tomasetto C,

Rio MC. Stromelysin-3 is a potent negative regulator of adipogenesis participating to cancer cell-adipocyte interaction/crosstalk at the tumor invasive front. Cancer Res. 2005;65(23):10862-10871.

86. Wen YA, Xing X, Harris JW, Zaytseva YY, Mitov MI, Napier DL, Weiss HL, Mark Evers B, Gao T. Adipocytes activate mitochondrial fatty acid oxidation and autophagy to promote tumor growth in colon cancer. Cell Death Dis. :017;8(2):e2593-e2593.

87. Picon-Ruiz M, Pan C, Drews-Elger K, Jang K, Besser : H. Lhao D, Morata-Tarifa C, Kim M, Ince TA, Azzam DJ, Wander SA, Wang P Er sunul B, Datar RH, Cote RJ, Howard GA, El-Ashry D, Torné-Poyatos P, Mla rclal JA, Slingerland JM. Interactions between adipocytes and breast cancer cel s ', ti mulate cytokine production and drive Src/Sox2/miR-302b-mediated mali snc ht progression. Cancer Res. 2016;76(2):491-504.

88. Gomez-Chou SB, Swidnicka-Si - rgiejko AK, Badi N, Chavez-Tomar M, Lesinski GB, Bekaii-Saab T, Farren MR, Mure I A, Schmidt C, Liu Y, Deng D, Hwang RF, Zhou L,

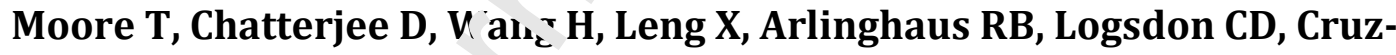
Monserrate Z. Lipocai: $n-2$ promotes pancreatic ductal adenocarcinoma by regulating

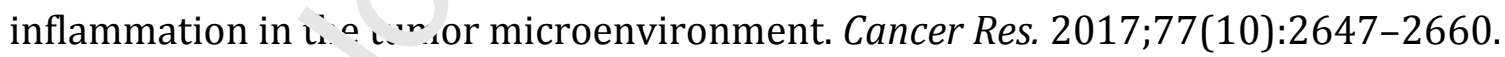

89. Zhang Y, Daquinag AC, Amaya-Manzanares F, Sirin O, Tseng C, Kolonin MG. Stromal progenitor cells from endogenous adipose tissue contribute to pericytes and adipocytes that populate the tumor microenvironment. Cancer Res. 2012;72(20):5198-5208. 
Fig. 1. miR-221-3p attenuates lipid accumulation during SGBS adipocyte differentiation. A) To assess miR-221-3p's role in terminal differentiation, adipocytes where transfected with nontargeting siRNA (NT), miR-221-3p mimic (miR-221-3p) or miR-221-3p inhibitor (anti-miR221-3p) on day 6 of differentiation. B) Triglyceride content in SGBS on day 13 transfected on day 6 (n=8, two independent experiments) C) Average lipid droplet area per cell quantified from lipid droplet staining. Approximately 500 cells were quantified. D) Lipid droplet staining (Bodipy) of mature SGBS adipocytes transfected on day 6 (n=2, two independent experiments). The quantifications are expressed as percentage ., where NT is 100\% (indicated by a dotted line). The data is represented as mean witı. Sr. Statistical significance is designated as $* P \leq 0.05,{ }^{* *} P<0.01$.

Fig. 2. miR-221-3p dampens the terminal differentla ${ }^{\text {ion }}$. of adipocytes. A) mRNA expression of adipogenesis markers on day 13, after $t$ a's ection of the adipocytes on day 6 of differentiation ( $\mathrm{n}=5-7$, two independent $f$ <p $\mathrm{f}$ rimınts). B) Quantification of protein expression of SCD1 and adiponectin (AdipoQ) in cells transfected with NT or miR-221-3p (n=7-8, two independent experiments). Represent ${ }_{t}$ tive western blots are shown on the right. Immunodetected bands are shorvn + the top and total protein below. The data is represented as mean with SD. Statistical s. rnilicance is designated as ${ }^{*} P \leq 0.05,{ }^{* *} P<0.01,{ }^{* * *} P<0.001$.

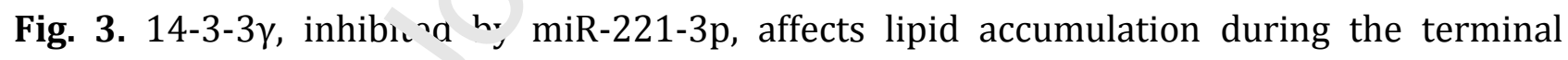
differentiation of SGBS adıpocytes. A) The seed sequence of miR-221-3p matches the 3'UTR of

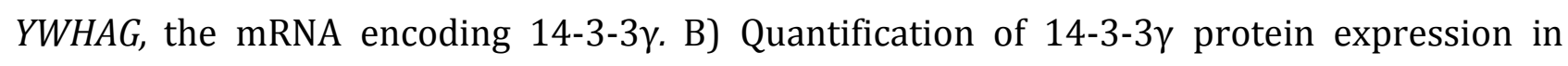
mature SGBS transfected with non-targeting siRNA (NT), miR-221-3p mimic (mir-221-3p) or mir-221-3p inhibitor (anti-miR-221-3p; $n=8$ two independent experiments). The level in NT is indicated with a dotted dine. Representative immunoblots are shown on the right: immunodetected bands are displayed at the top and the total proteins in the lanes below. C) Triglyceride content in mature SGBS adipocytes transfected with Silencer Select $2^{\text {TM }}$ nontargeting control (SS2) or YWHAG siRNA on day 6 of differentiation (n=9-10, two independent 
experiments). D) Lipid droplet area per cell quantified from the lipid droplet staining. Approximately 500 cells were quantified. E) Lipid droplet staining (Bodipy) of mature SGBS adipocytes transfected on day 6 of differentiation $(n=2$, two independent experiments). The data is represented as mean with SD. Statistical significance is designated as ${ }^{*} P \leq 0.05,{ }^{* *} P<$ 0.01 .

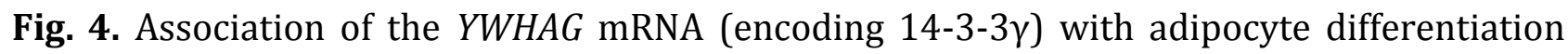
markers in vitro and in vivo. A) mRNA expression of adipocyte differentiation markers in mature SGBS cells that were transfected with Silencer Select iM non-targeting control (SS2) or $Y W H A G$ siRNA on day 6 of differentiation $\left(n=6\right.$, two indep $n$ nd $\_n t$ experiments). The data is represented as mean with SD. Statistical significance is lesignated as ${ }^{* *} P<0.01$. B-E) $Y W H A G$ mRNA correlates with stearoyl-CoA desaturase-1 isCI 1; B), AHNAK protein (C), glucose transporter 4 (GLUT4; D) and fatty acid syntr ase (FAS; E) mRNA in human subcutaneous adipose tissue $(n=30)$. The $P$ and $r$ values sre ina cated in the respective panels.

Fig. 5. Impact of miR-221-3p on $d_{i}{ }^{c}{ }^{c}$ erentiation markers in mature adipocytes. A) SGBS adipocytes were transfected with non ca!geting siRNA (NT) or miR-221-3p mimic (miR-221$3 p)$ at the mature stage, on d.iy $: 3$ of differentiation. B) mRNA expression of adipocyte differentiation markers on tay 16, after transfection on day 13 (n=4-7. 3 independent experiments). C) Quaı ${ }^{2} \mathrm{it}_{\mathfrak{2}}$, on of protein expression of adiponectin (AdipoQ) in cells transfected with non-targeting siRNA (NT) or miR-221-3p mimic (miR-221-3p; $n=4$, two independent experiments). Representative western blots are shown: immunodetected bands on the left and total protein on the right. D) Triglyceride content in SGBS on day 16, after transfection on day 13 ( $n=6$, two independent experiments). The data is represented as mean with SD. Statistical significance is designated as ${ }^{*} P \leq 0.05,{ }^{* *} P<0.01,{ }^{* * *} P<0.001$.

Fig. 6. The effect of miR-221-3p on adipocyte lipid composition. A) Total lipid classes in miR221-3p mimic transfected mature adipocytes $(n=4)$. Significantly altered classes are marked with an asterisk. B) Individual affected species in the significantly affected classes. The most 
affected species are identified (see other significantly altered species in section 3.3). The three horizontal lines illustrate P values. The vertical dotted line indicates non-targeting siRNA (NT) in both panels. TG, triglycerides; DG, diglycerides; LPC, lyso-phosphatidylcholines; PE P, phosphatidylethanolamine plasmalogens; HexCer, hexosylceramides; Cer, ceramides; SM, sphingomyelins; PC O, phosphatidylcholine ethers; PC, phosphatidylcholines; PI, phosphatidylinositols; PG, phosphatidylglycerols; PS, phosphatidylserines; PE, phosphatidylethanolamines; LPE, lyso-phosphatidylethanolamines.

Fig. 7. miR-221-3p overexpression inhibits ASAH1, MOGAT an. ACLY expression and de novo lipogenesis. A) Expression of the indicated mRNAs in $\Lambda^{T}$. nd miR-221-3p transfected adipocytes (n=3-6, two independent experiments). B) P ottill expression of ASAH1 and ACLY in cells transfected with non-targeting siRNA (NT) ८ * miR-221-3p mimic (miR-221-3p; $n=9$, three independent experiments). Representat $\mathrm{V}^{\prime}$ - vestern blots are shown on the right: immunodetected bands are shown at th $\_\mathrm{t}, \mathrm{p}$, and total protein at the bottom. C) De novo lipogenesis of cholesterol (Chol), DG ^nd TG, as measured by [ ${ }^{3} \mathrm{H}$ ]acetic acid incorporation $(n=12$, two independent experimel.t.). NT is represented by a dotted line. The data is represented as mean with $\mathrm{SD}$. Sta 'stical significance is designated as ${ }^{*} P \leq 0.05,{ }^{* *} P<0.01$, $* * * * P<0.0001$.

Fig. 8. Role of miR-2 $\iota^{1}-n_{1}^{n}$ in the tumor microenvironment. A) miR-221-3p expression in tumor proximal adipose tissue of breast carcinoma patients $(n=47$; grade I, $n=14$; grade II, $\mathrm{n}=15$; grade III, $\mathrm{n}=18$ ). B) miR-221-3p negatively correlates with adiponectin (AdipoQ) mRNA in thesse breast adipose biopsies. $\mathrm{P}$ and $\mathrm{r}$ values are indicated in the panel $(n=47) . C-D)$ Outlines of in vitro medium transfer experiments. C) Cancer conditioned serum-free medium (SFM), designated CCM, was collected from MCF-7 breast cancer cells and incubated with SGBS adipocytes. D) Adipocyte conditioned SFM, designated ACM, was collected from mature SGBS transfected with non-targeting siRNA (NT) or miR-221-3p mimic (miR-221-3p), and incubated with MCF-7 cells. E) Expression of miR-221-3p (E), of inflammatory marker mRNAs 
(F) and of lipogenic marker mRNAs (G) in mature SGBS adipocytes treated with SFM or CCM $(n=5-10$, two to three independent experiments). Invasion $(H)$ and proliferation (I) rate of MCF-7 cells treated with NT ACM or miR-221-3p ACM (n=6-9, three independent experiments). The data is represented as mean with SD. Statistical significance is designated as ${ }^{* *} P<0.01,{ }^{* * *} P<0.001,{ }^{* * * *} P<0.0001$.

Table 1. Clinical characteristics of subjects undergoing reduction mammoplasty or mastectomy.

\begin{tabular}{|c|c|c|}
\hline & $\begin{array}{l}\text { Reduction mammoplasty } \\
(\mathrm{n}=30)\end{array}$ & Bre st cancer $(n=47)$ \\
\hline Age, $y^{a}$ & $46(21-77)$ & טu (29-89) \\
\hline Postmenopausal, \% & $45(13)$ & $68(32)$ \\
\hline BMI, $\mathrm{kg} / \mathrm{m}^{2 \mathrm{a}}$ & $28(18-38)$ & $25(19-40)$ \\
\hline WHR A.U. ${ }^{a}$ & $0.88(0.7 \Gamma-0 . \overline{9})$ & $0.87(0.63-0.99)$ \\
\hline Hypertension, \% ${ }^{b}$ & $17(5)$ & $30(14)$ \\
\hline Hypercholerterolemia, \% ${ }^{b}$ & $14(4)$ & $23(11)$ \\
\hline Type 2 diabetes, $\%$ b & $(2)$ & $13(6)$ \\
\hline
\end{tabular}

a The data are expressed as mi di $\cdot n$ (range).

b The data are expressed \& $\varsigma$ percentages (n). 


\section{Declaration of competing interest}

The authors have no conflicts of interest to disclose concerning the work reported in this manuscript. 


\section{Author contributions}

M.A.A., M.Y.A., S.J.P., M.H. and P.A.N.H. carried out the experimental work and analyzed data. M.L. obtained the tissue specimens of human subjects and edited the manuscript. G.L., P.F.-P., M.W., T.S.M., K.T., H.S.-P., P.A.N.H. and V.M.O. conceived the research, supervised the work, and edited the manuscript, which was written by M.A.A., M.Y.A., P.A.N.H. and V.M.O. 


\section{Highlights}

- $\quad$ miR-221-3p suppresses adipogenesis, putatively mediated by 14-3-3 $\gamma$ downregulation

- $\quad$ miR-221-3p suppresses de novo lipogenesis in adipocytes

- miR-221-3p alters adipocyte ceramide, sphingomyelin and diacylglycerol content

- miR-221-3p expression is elevated in adipocytes adjacent to breast carcinoma

- Adipocyte miR-221-3p elevation may promote metabolic disease and cancer progression 


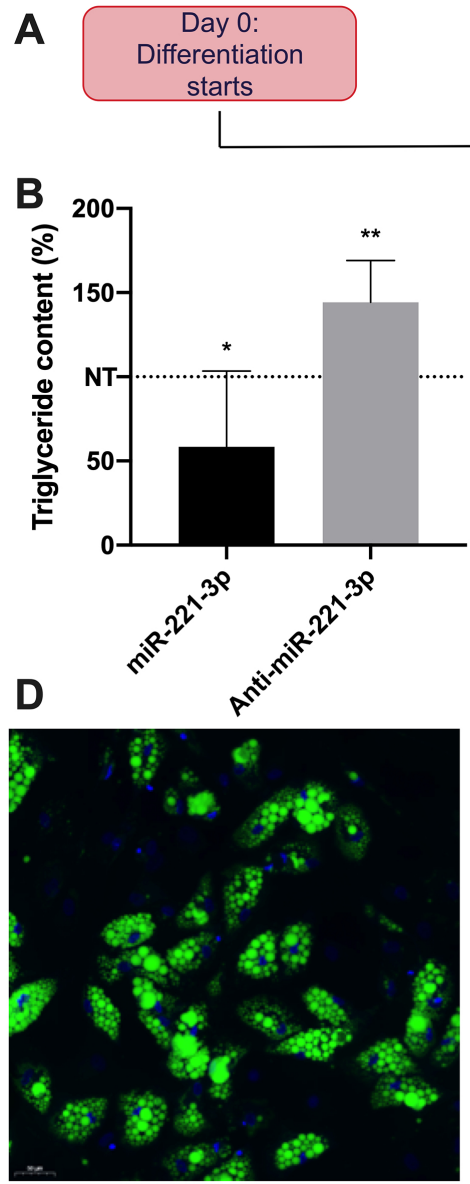

NT DAPI Bodipy

\section{$\mathrm{B}$}

Day 6:

Transfection
Day 8:

Differentiation

medium added
Day 13-14: Cells are lysed or fixed

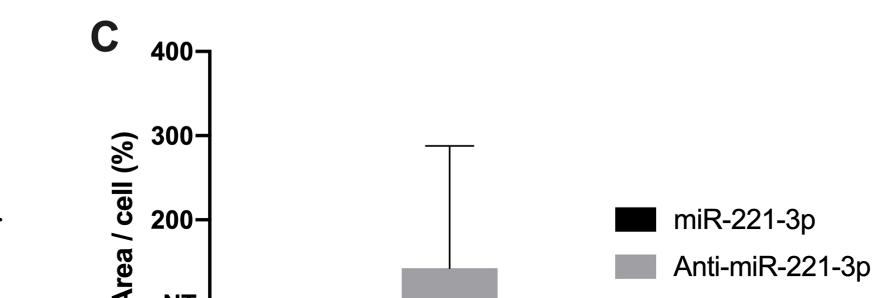



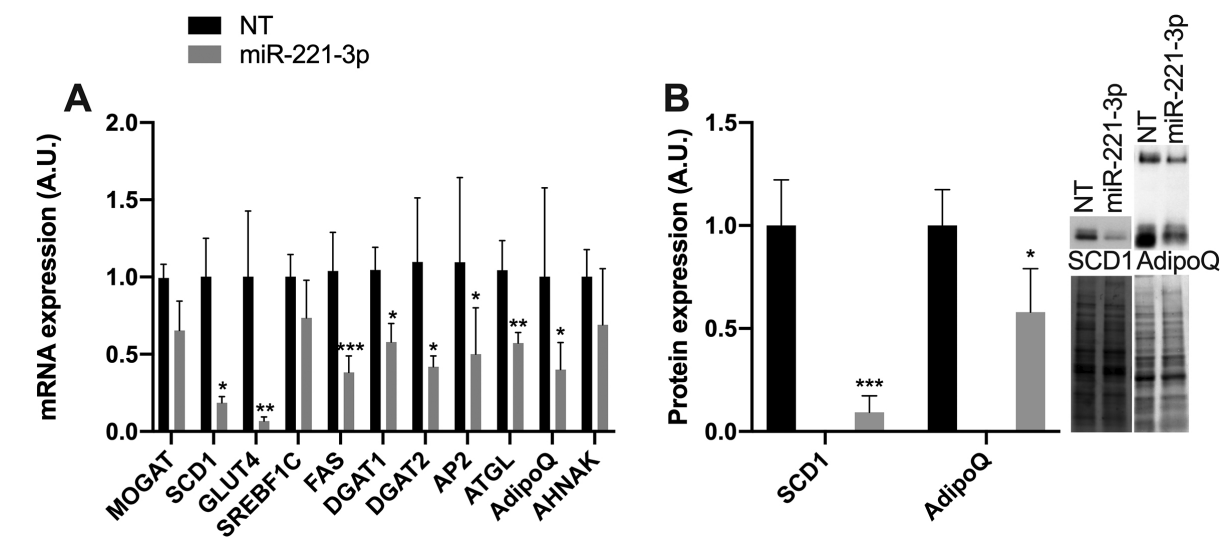

Figure 2 
A 3' CUUUGGGUCGCUGUUACAUCGA 5' miR-221-3p

5' UGAAUGUGAGUCAUUAUGUAGCU 3' YWHAG

B
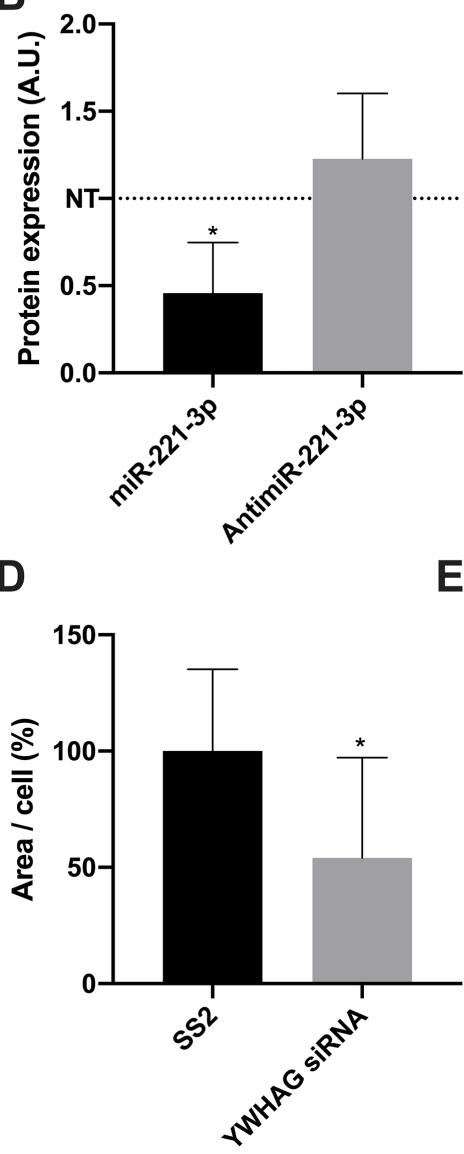

E

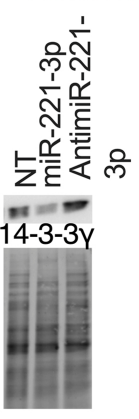

C

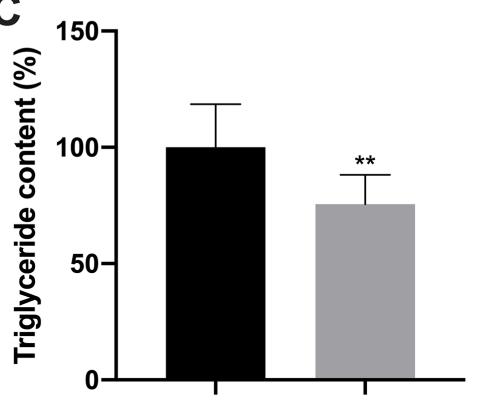

$5^{5^{2}}$
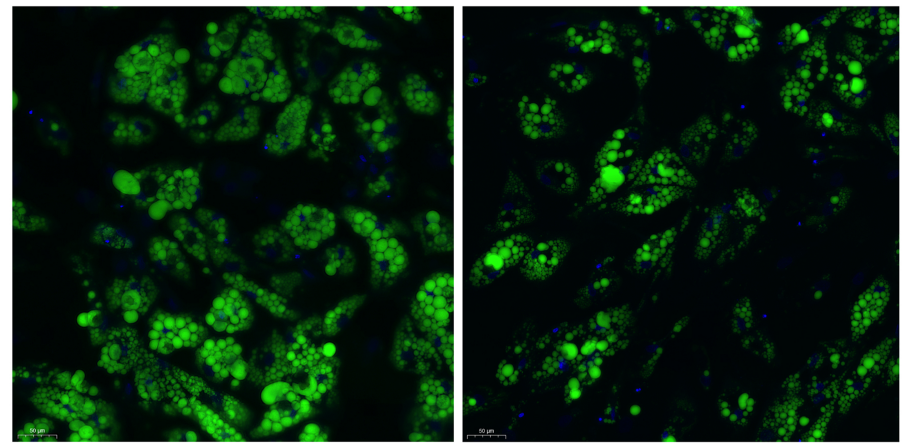

SS2 DAPI Bodipy

Figure 3 


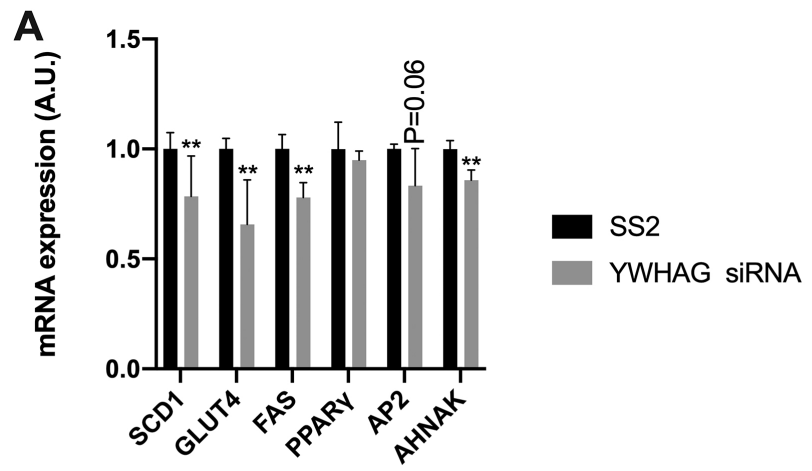

B
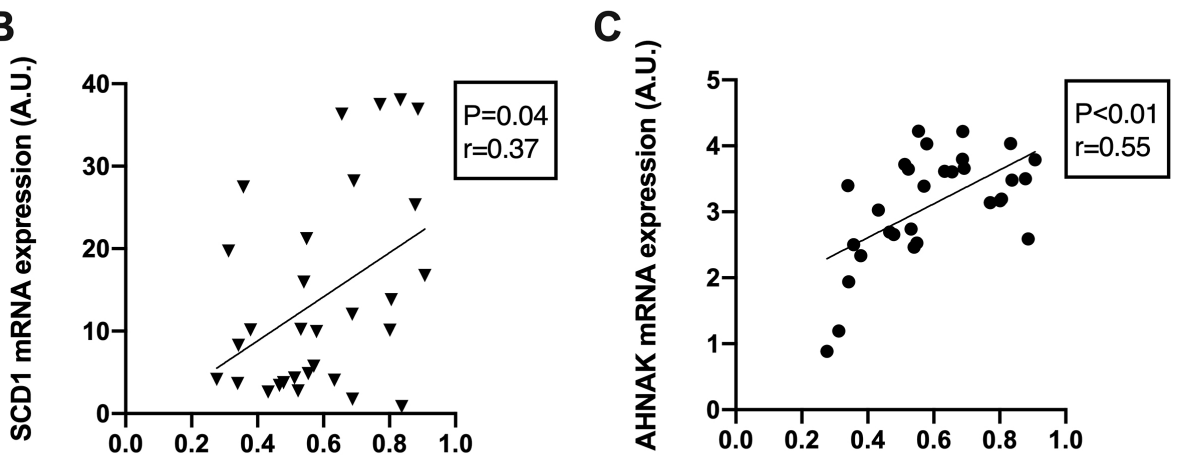

D YWHAG mRNA expression (A.U.) E

E YWHAG mRNA expression (A.U.)

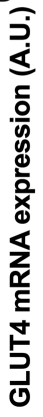

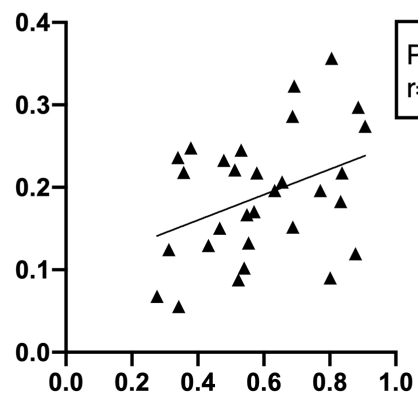

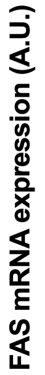
YWHAG mRNA expression (A.U.)

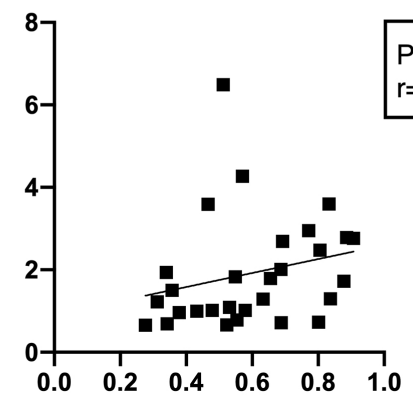
YWHAG mRNA expression (A.U.) 


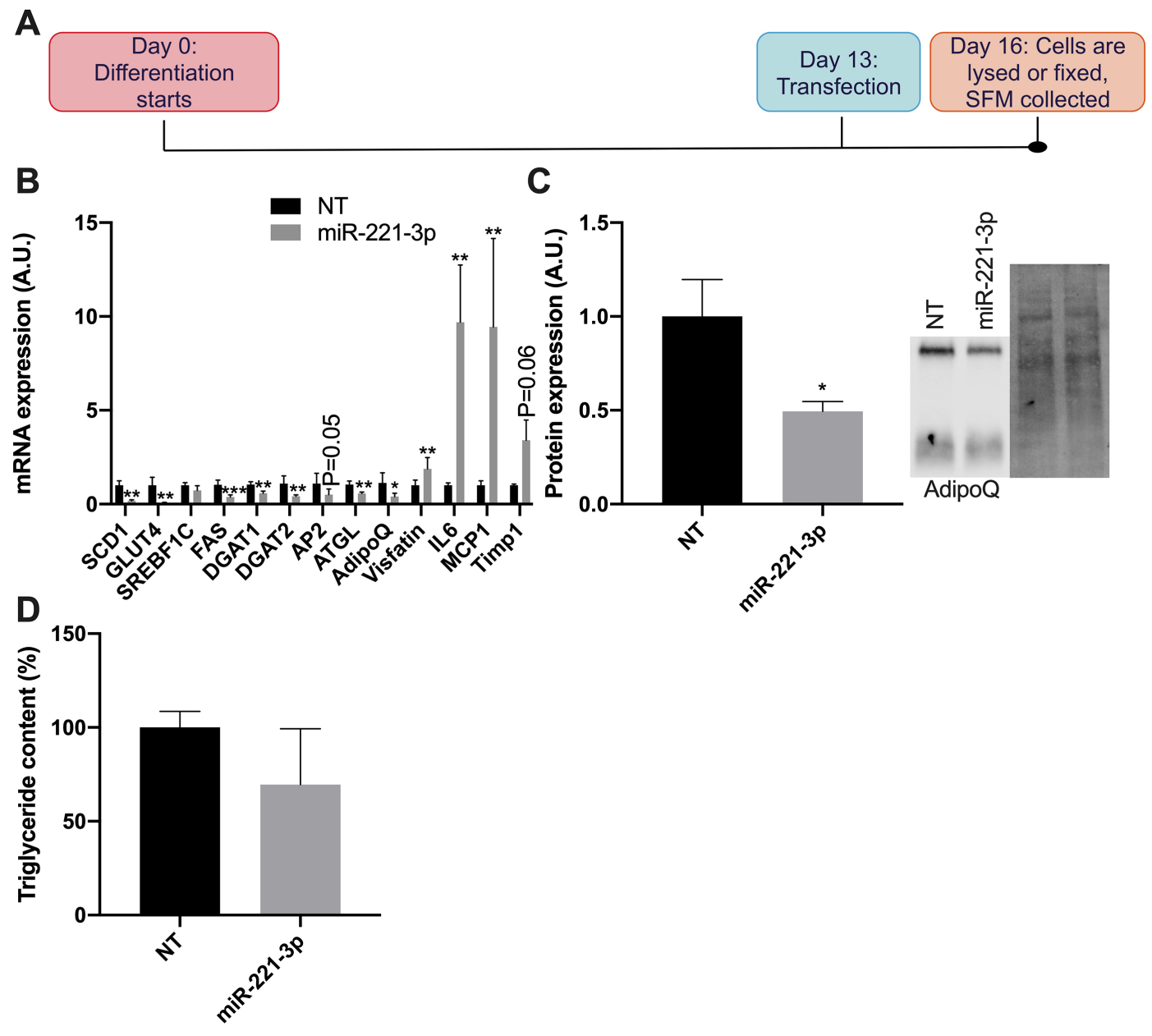

Figure 5 


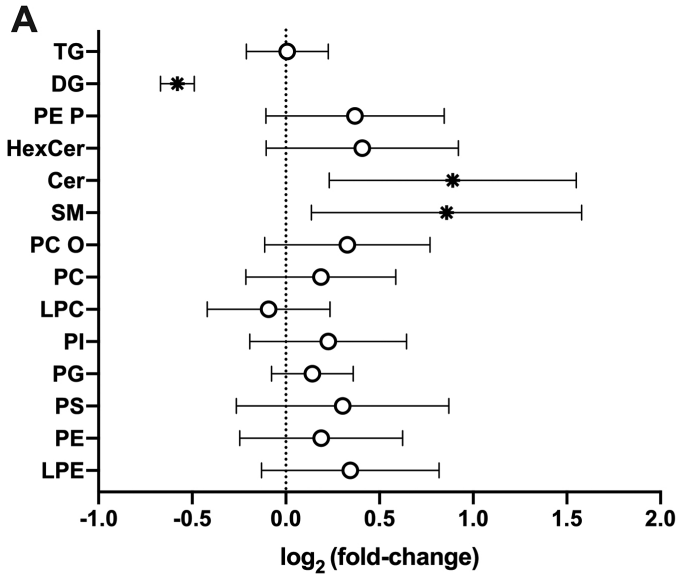

B

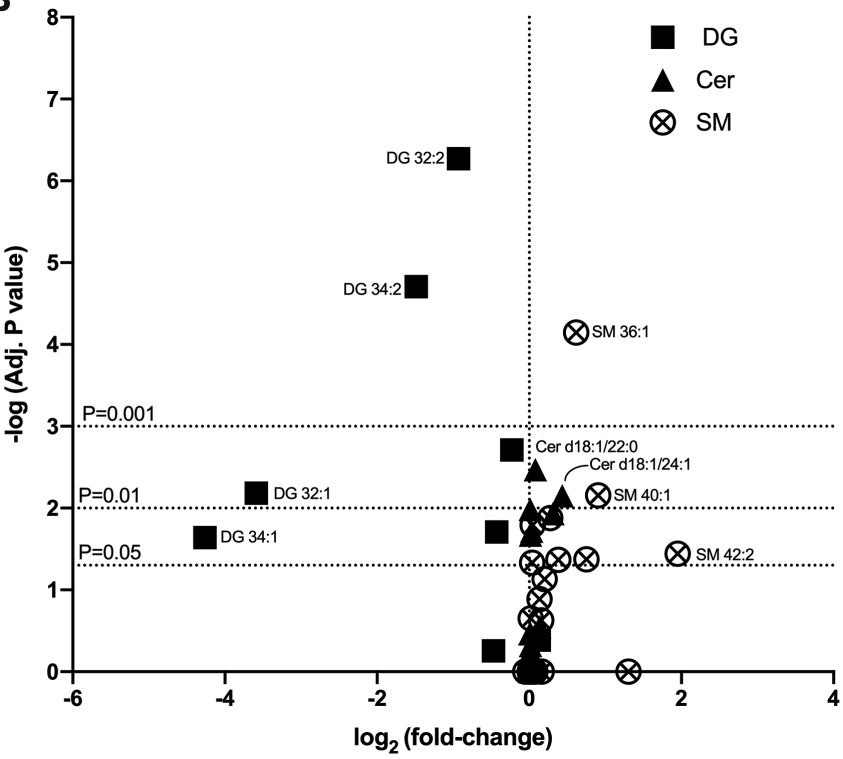

Figure 6 
A

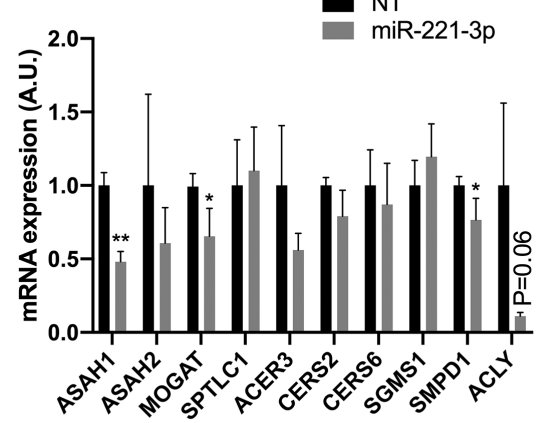

C

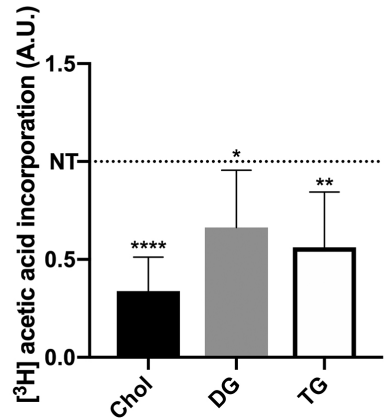

B

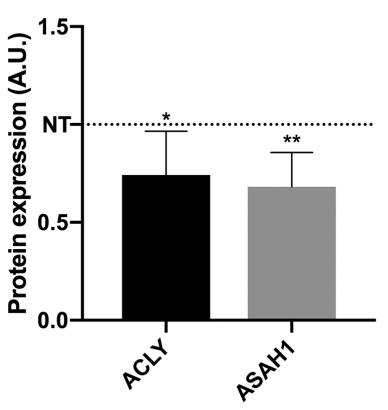

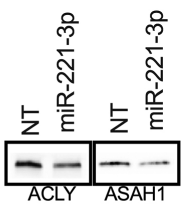

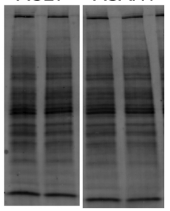

Figure 7 
A

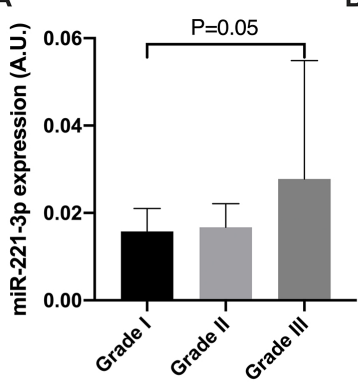

B

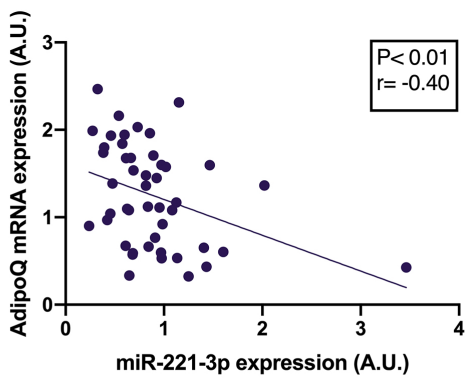

C

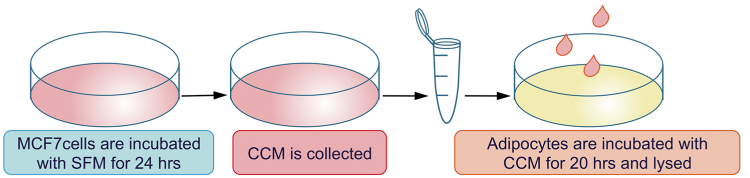

D

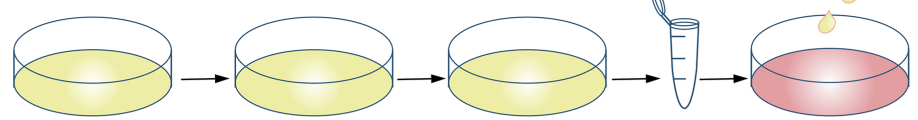

Day 13: Transfection of SGBS

Day 16: Transfection

Day 17: ACM NT and ACM

MCF7 cells are incubated with ACM before complex replaced with SFM

miR-221-3p are collected

migration and proliferation experiments

E
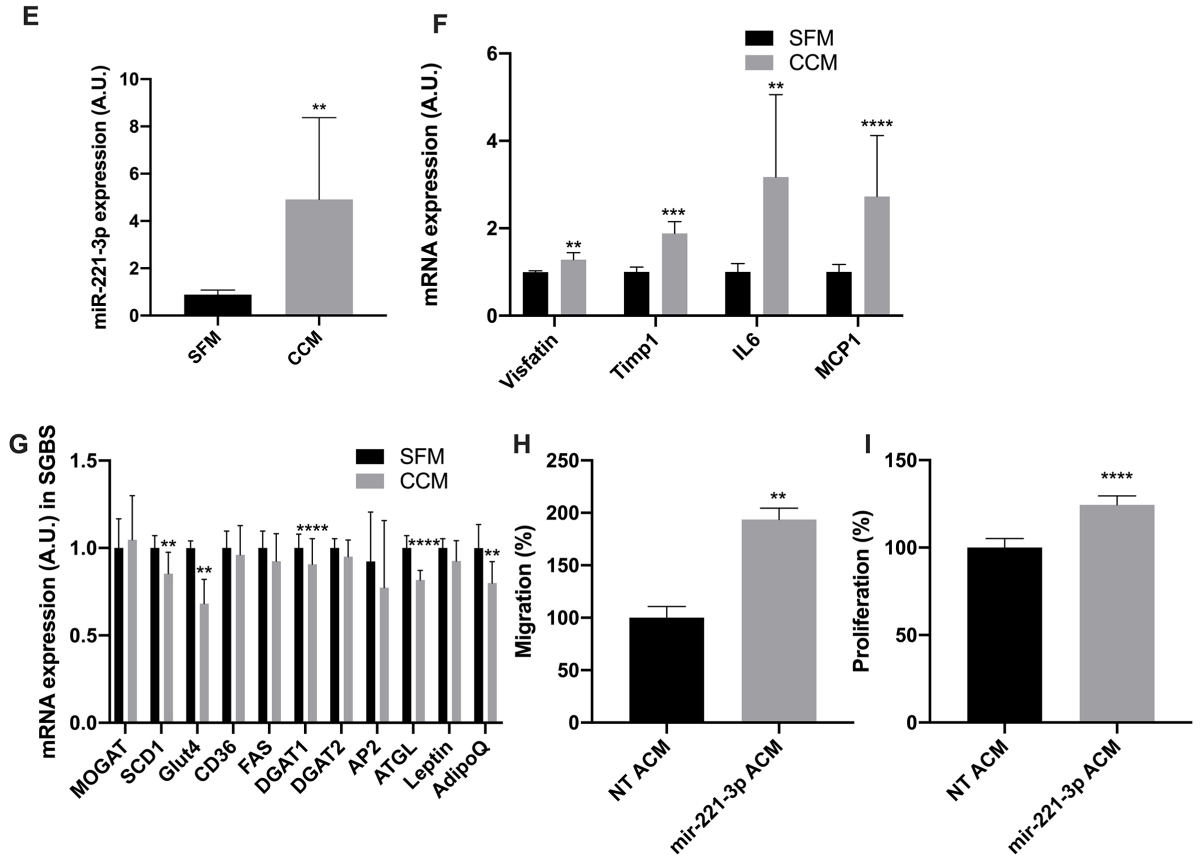